\title{
MINIMALISMO E INCREMENTALISMO CONSTITUCIONAL
}

\section{CONSTITUTIONAL MINIMALISM AND INCREMENTALISM}

\author{
José Francisco García GarCíA ***
}

\begin{abstract}
RESUMEN: Este artículo desarrolla aspectos centrales de una aproximación minimalista a la Constitución y al cambio constitucional. El autor sugiere que la Constitución no busca ni pretende zanjar las controversias sociales fundamentales; no es la Constitución un proyecto acabado, un estado o etapa final, sino una actividad; y su contenido estar basado en arreglos institucionales predominantemente orgánicos y procedimentales. Respecto del cambio constitucional se destaca la idea de renegociación constitucional; la importancia de minimizar la distinción entre política constitucional y política ordinaria; y recalca la particular solemnidad de la reforma constitucional. El autor utiliza esta aproximación minimalista para examinar algunos temas controversiales del debate constitucional actual en Chile.
\end{abstract}

Palabras clave: Minimalismo, incrementalismo, reforma constitucional, proceso constituyente.

ABSTRACT: This article develops key elements of a minimalist approach to the Constitution and to constitutional change. The author suggests that the constitution must not pretend to solve fundamental social controversies, nor is the constitution and end state, but an activity; and its content predominantly related to structural and procedural rules. Regarding constitutional change, it is highlighted the idea of constitutional renegotiation; the importance of minimizing the distinction between constitutional politics and ordinary politics; and emphasize the particular solemnity of constitutional amendment. The author applies this minimalist approach to examine some controversial aspects of the ongoing Chilean constitutional debate.

Key words: Minimalism, incrementalism, constitutional amendment, constitution making process.

\section{INTRODUCCIÓN}

Thomas Jefferson, uno de los "padres fundadores" norteamericanos, sostuvo que la tierra pertenecía a los vivos y que cada Constitución naturalmente expiraba a los diecinueve años -ciclo que Jefferson asociaba a una generación-. De lo contrario, las futuras generacio-

\footnotetext{
* Abogado. Licenciado en Derecho y Magíster en Derecho Público (Constitucional), P. Universidad Católica de Chile. Máster y Doctor en Derecho, Universidad de Chicago. Profesor de Derecho Constitucional, P. Universidad Católica de Chile. Correo electrónico: jfgarcia@uc.cl.

** Agradezco los comentarios y/o aportes de los profesores Sergio Verdugo, José Manuel Díaz de Valdés, Luis Cordero, Patricio Zapata, Javier Couso, Jorge Correa y Jorge Contesse. También de los dos árbitros anónimos. Asimismo, agradezco la hospitalidad y un ambiente intelectual estimulante en el Centre for Socio-Legal Studies de la Facultad de Derecho de la Universidad de Oxford, donde realicé una estadía postdoctoral en 2013, desarrollando los aspectos centrales de este artículo. Todas las traducciones son responsabilidad del autor.
} 
nes serían gobernadas por la "mano de los muertos". James Madison, por el contrario, no solo respondió que eso generaría un sistema altamente inestable, sino que las constituciones debiesen perdurar en el tiempo y ser modificadas de manera excepcional, extraordinaria ${ }^{1}$.

Una versión más moderna del planteamiento de Jefferson -aunque de alcance más amplio, y para Bellamy más plausible ${ }^{2}$ - se encuentra en el trabajo de Bruce Ackerman ${ }^{3}$. El autor sostiene que la Constitución (norteamericana) descansa en un modelo "dualista" de decisiones democráticas, distinguiendo entre aquellas tomadas por el pueblo, de aquellas otras tomadas por el gobierno y sus representantes. La primera ocurre excepcionalmente, bajo especiales condiciones constitucionales; la segunda, frecuentemente. La primera abre espacio al periodo de "política constitucional"; la segunda a la "política ordinaria"

Así, el modelo dualista busca desafiar el modelo "monista" -siendo una versión idealizada del modelo parlamentario británico el paradigma según Ackerman-, centrado en la idea de que el grupo político que gana las elecciones tiene plena autoridad en materia de creación de normas, incluyendo decisiones del ámbito de la política constitucional. Ackerman defiende la revisión judicial de las leyes, pues fortalece la democracia y defiende en épocas de política ordinaria las decisiones de la política constitucional, superando la "dificultad contramayoritaria"', identificando tres momentos constitucionales específicos en el caso norteamericano: la fundación, la reconstrucción y el New Deal ${ }^{6}$.

La idea de que las constituciones deben gobernar solo a la generación que la instituyó 7 , o solo tras intervalos determinados de tiempo o ante momentos constitucionales, y siguiendo determinados rituales formales bajo condicionales especiales, se abre un espacio para el cambio constitucional, reflejan una forma de entender este de manera equivocada. Se trata de

1 Una buena síntesis del debate entre Madison y Jefferson puede encontrarse en Sunstein (2009) y Bellamy (2010).

2 Bellamy (2010) p. 153.

3 Ver especialmente ACKERMAn (1991), (1995) y (1998). Más recientemente ver del autor (2011).

4 Podemos sintetizar las "especiales condiciones constitucionales" de Ackerman de la siguiente forma: un movimiento político que quiere actuar a nombre del pueblo debe convencer a un número extraordinariamente alto de conciudadanos para considerar la iniciativa con una seriedad que, ordinariamente, no es parte del debate político; se debe permitir a los oponentes organizarse; y, se debe convencer a la mayoría de los conciudadanos de apoyar esta iniciativa mientras se discute su mérito, en el foro deliberativo generado para una "creación normativa superior" (higher law making). ACKERMAN (1991) p. 6.

5 En efecto, para Ackerman, bajo la lógica dualista, la Corte Suprema norteamericana en general, y la revisión judicial de leyes en particular, aparece bajo un prisma diferente, una función preservadora, que puede bloquear los intentos de pasar por encima de los principios constitucionales establecidos mediante una ley. ACKERMAN (1991) p. 10. La "dificultad contramayoritaria" fue desarrollada por BICKEL (1986).

${ }^{6}$ Literatura crítica de la tesis de Ackerman puede encontrarse en ChOudhry (2008). Asimismo, ver BelLamy (2010) pp. 147-53.

7 Varol ha buscado revitalizar esta tesis, pero sobre la base de una argumentación que busca conversar con tesis gradualistas, proponiendo "constituciones temporales" o cláusulas constitucionales temporales. Para el autor, ambas pueden ser particularmente útiles para conseguir cuatro objetivos: promover el gradualismo y la experimentación cuando los costos de equivocarse en el diseño constitucional son altos; reducir sesgos por problemas cognitivos cuando estos pueden predominar en el proceso de creación de una Constitución; facilitar la construcción de consensos cuando los costos de alcanzarlo son altos; y disminuir el peso de la "mano de los muertos", con un menor control de los cambios a la Constitución por parte de los creadores de la Constitución original. Ver VAROL (2013). 
una aproximación maximalista, amplificada, por un lado, por una mirada romántica y perfeccionista acerca de la Constitución como un acuerdo completo, terminado, la fase final de un momento constitucional; y, por el otro, con la necesidad de dotar al texto constitucional en lo sustantivo, con una serie de reglas orgánicas y procedimentales, y un catálogo abultado de derechos, que busca generar un impacto transformador en la sociedad ${ }^{8}$.

Lo anterior es relevante para quienes, en Chile, hablan hoy de un "momento constitucional"; con más o menos intensidad, como fuente de inspiración, o derechamente como un ethos para aproximarse al debate respecto del cambio constitucional'.

Contra la mirada maximalista, se opone y desarrolla en este artículo una mirada minimalista. Como quedará de manifiesto, no se trata de presentar un modelo, una escuela o una teoría sobre el sentido de una Constitución (y su contenido) y el cambio constitucional; se busca, simplemente, y de manera más modesta, sistematizar una serie de afluentes intelectuales que han ido generando un cierto cuerpo de ideas, una aproximación que valora una Constitución que establece las reglas básicas de la comunidad política (minimalismo sustantivo) y la importancia de los cambios incrementales (minimalismo formal). Se trata de un enfoque que valora la tradición constitucional y está atento a la evidencia empírica disponible. Se trata en suma, de una aproximación que descansa en la evolución constitucional, valorando de manera racional y crítica los arreglos constitucionales existentes, abierta al cambio, más que a una transformación radical, un nuevo big-bang.

Para profundizar en los objetivos planteados, el presente artículo continúa de la siguiente manera. En la sección 2, se caracteriza el enfoque minimalista sobre la base de literatura especializada reciente, sistematizándose ideas relevantes para efectos de la discusión chilena. También se enuncian algunas críticas relevantes que se han formulado a esta aproximación. En la sección 3, se avanzan ciertos lineamientos respecto de cómo, desde una aproximación minimalista, se puede enfocar la discusión en Chile; examinándose brevemente, ciertos elementos de contexto involucrados, para pasar a analizar algunos déficits y controversias constitucionales desde el prisma del minimalismo, intentando entregar ciertas orientaciones para enfrentarlas de manera constructiva. Finalmente, se entregarán las conclusiones más relevantes del artículo.

\section{MINIMALISMO E INCREMENTALISMO: CONSTITUCIÓN Y CAMBIO CONSTITUCIONAL}

Desde la perspectiva del sentido y el contenido de una Constitución, el minimalismo es una aproximación modesta, realista, frente al pacto social: cómo establecer reglas básicas,

\footnotetext{
8 Entiendo por aproximación maximalista a la Constitución el intento de regular materias adicionales a las reglas orgánicas y procedimentales básicas, como asimismo de los derechos civiles y políticos clásicos. Ejemplo de ello se encuentra en diversas constituciones latinoamericanas que han constitucionalizado una serie de reglas de naturaleza legal, especialmente de protección social. Maximalismo, desde la perspectiva del cambio constitucional, lo entiendo como la aspiración de lograr un transformación radical de las reglas existentes, desde una hoja en blanco, que no considera la tradición constitucional existente, las prácticas constitucionales (legislativas, judiciales, administrativas, ect.), la evidencia, incluyendo formas de cambio extrainstitucionales.

9 Ver introducción de la sección 3 del artículo.
} 
un mínimo común denominador, en una sociedad plural, cruzada por diferencias profundas en cuestiones religiosas, políticas, culturales, etc. Una segunda dimensión, que también es enfrentada de manera minimalista, esto es, con la misma actitud modesta y realista anterior, dice relación con el cambio constitucional. En esta dimensión entendemos el minimalismo como incrementalismo, gradualismo. Ambas son formas de minimalismo; ambas descansan en la idea de evolución constitucional por sobre transformaciones radicales.

Como se podrá observar a continuación, el minimalismo va entrecruzando ambos aspectos (minimalismo sustantivo e incrementalismo). Solo para efectos de sistematizar la literatura examinada de forma pedagógica, se separarán ambas dimensiones: el sentido de la constitución y del cambio constitucional. Posteriormente, se sistematizarán y destacarán los principales elementos y aportes de esta literatura, junto con exponer, de manera sintética, algunas críticas relevantes que se han formulado a esta aproximación.

\subsection{Minimalismo y Sentido de la COnStitución}

Como sostiene Sunstein, probablemente el autor que más contribuciones ha hecho al enfoque minimalista, las constituciones "son instrumentos pragmáticos, no guiones sobre una sociedad justa, y, por tanto, existe una brecha entre lo que las constituciones dicen y lo que la justicia requiere" 10 .

En este sentido, hay cuatro aspectos que parece relevante destacar respecto del sentido de la Constitución bajo el prisma minimalista, aquel que rescata la modestia de la empresa constitucional: (1) la Constitución no zanja las controversias sociales fundamentales; (2) la Constitución no es un proyecto acabado, un estado o etapa final, sino una "actividad”; y (3) una Constitución solo debe contener reglas básicas, tanto en lo orgánico como desde la perspectiva del catálogo de derechos.

\subsubsection{La Constitución no busca (ni debe) zanjar las controversias sociales fundamentales}

Los teóricos del constitucionalismo deliberativo argumentarían que no podemos esperar que las constituciones resuelvan las controversias sociales fundamentales. Porque, como sostiene Lerner, al posponer decisiones constitucionales en temas fundacionales, el enfoque minimalista, recomienda adoptar las visiones alternativas que existen al interior de una sociedad sobre el Estado y su rol, y en la forma de abordar las diferencias políticas, culturales, religiosas, etc., y de este modo, representa la identidad real de "el pueblo" en el momento constituyente, esto es, una identidad dividida ${ }^{11}$. En efecto, el diseño de una Constitución bajo condiciones de desacuerdos profundos requiere de un enfoque innovador: "la promulgación de arreglos constitucionales rígidos y supremos, que establecerán restricciones a las futuras generaciones es comprendido como una decisión forzosa e inequívoca entre modelos alternativos de normas e identidades" 12 .

\footnotetext{
10 Sunstein (2001) p. 10.

11 Lerner (2013) p. 7. Ver también Lijphart (2004).

12 LeRner (2013) p. 39.
} 
Sunstein ha abordado también esta cuestión. Para el autor, las personas pueden frecuentemente estar de acuerdo en prácticas constitucionales, e incluso en los derechos constitucionales, cuando no pueden estar de acuerdo en teorías constitucionales, y así "órdenes constitucionales en forma tratan de resolver problemas, incluidos los problemas vinculados a la deliberación, conviniendo acuerdos teóricamente incompletos (incompletely theorized agreements)" 13 . Acuerdos teóricamente incompletos "toman la forma de decisiones incrementales, construyendo cuidadosamente sobre lo que ha sido dicho en el pasado" 14 .

Es precisamente por lo anterior, que Lerner recomienda que las decisiones constitucionales requieren de la búsqueda de consensos, y no de la aplicación irrestricta del principio democrático básico (la regla de mayoría). La regla de mayoría tiene un valor limitado en sociedades divididas cuando está en juego la necesidad de resolver controversias fundamentales ${ }^{15}$.

Ahora bien, el que las constituciones no sean instrumentos para zanjar las controversias sociales fundamentales, no implica que la Constitución no tenga una actitud proactiva frente a estos. No se trata de simplemente dejar las controversias de lado. En efecto, quienes intervienen en el proceso constitucional (redactores de una nueva Constitución o parlamentarios como constituyente derivado) no cierran los ojos a las tensiones, sino que, en cambio, deciden acoger las visiones alternativas en pugna. Ello implica, por ejemplo, incluir en la constitución, las diferentes visiones, aunque sean mutuamente contradictorias ${ }^{16}$. Una Constitución como esta, sostiene Lerner, adoptada por una sociedad dividida, refleja entonces la identidad de "el pueblo" en su verdadero estado durante el proceso constituyente, el de un pueblo dividido. Lo anterior es posible de conseguir dado que existen diversas estrategias constitucionales, tales como el evitar la toma de decisiones [específicas], el uso de lenguaje jurídico ambiguo, o incluso, la introducción de cláusulas contradictorias en la Constitución, para hacerlo posible ${ }^{17}$.

13 SUnstein (2001) p. 50.

${ }^{14}$ Sunstein (2001) p. 63.

15 Lerner (2013) p. 41. Para Lerner, "subyace a este idea, que es una amenaza común en los procesos constituyentes de sociedades dividas, el que la democracia no puede sobrevivir si está basada solamente en la regla de mayoría, y que las decisiones que definen al colectivo deben estar basadas en más amplio consenso posible. Y si este consenso amplio no existe al momento de redactar una constitución, entonces este argumento juega a favor de posponer decisiones hasta que llegue el momento en que estos temas relevantes puedan ser formulados de una forma que sean aceptados de manera amplia”. LERNER (2013) p. 41.

${ }^{16}$ Lerner (2013) p. 43.

17 Lerner (2013) p. 43. Lerner analiza el caso de la Constitución española de 1978, que utilizó una fórmula constitucional ambigua en su intento de generar consenso respecto de la "cuestión nacional": "El artículo 2 representa las visiones alternativas existentes respecto de la identidad española, al reconocer, al mismo tiempo, tanto la unidad de la "nación española" como el derecho fundamental a la autonomía de las "nacionalidades" regionales, derecho que precede al orden constitucional mismo. Esta paradójica concepción de la nación española incrustada en el texto constitucional fue acompañada de la decisión de sus redactores de determinar los contornos y el alcance de las instituciones y mecanismos de las autonomías regionales españolas fuera del texto constitucional en el Título VIII. Sin embargo, finalmente, el comité que debía redactar dicho título no llegó a un consenso y acordó que tenían un desacuerdo, y así dejaron la decisión respecto de la futura organización territorial del Estado español al periodo de política "normal". El Título VIII nada dijo respecto de los límites territoriales de las diferentes regiones, y el alcance y contenido del "derecho al autogobierno" de las regiones, y ni siquiera clarificó la distinción entre los derechos reconocidos y garantizados a las "nacionalidades" en oposición a las "regiones". Lerner (2013) pp. 10-11. Asimismo, los tres casos principales analizados en su investiga- 


\subsubsection{La Constitución no es un proyecto acabado o una etapa final}

Gregoire Webber ha articulado una interesante crítica a la dogmática constitucional y a su obsesión de mirar la Constitución como estado final (end-state). Para el autor, "una Constitución no debe ser entendida como un proyecto terminado; más bien, y siendo consistente con la legitimidad política, se debe considerar a la Constitución como actividad"18. En efecto, el vocabulario de la dogmática constitucional "está repleto de referencias a la Constitución como "arraigada" (entrenched), "enclaustrada" (enshrined), "suprema" y "superior". Mientras que este vocabulario refleja la jerarquía de normas en un orden constitucional, también sugiere cierta permanencia" ${ }^{19}$.

Para Lerner esta concepción se vincula al ideal revolucionario que subyace a todo proceso constituyente: desde el siglo XVIII, las revoluciones exitosas han llevado al establecimiento de constituciones escritas que incorporan los logros sustantivos de dicha revolución. Segundo, redactar una nueva Constitución es en sí misma una oportunidad para el cambio social radical ${ }^{20}$. Este enfoque, sostiene, debe ser rechazado.

Así, la Constitución es establecida desde el origen, como un punto de referencia definitivo a partir del cual se le sitúa: como instrumento escrito, es el producto de un momento, un evento; no una historia: "La Constitución es un estado final, un proyecto acabado, una narrativa que solo puede empezar a terminar. Adquiere permanencia y estabilidad y continuidad, todo lo cual, asimismo, puede ser remitido al momento fundacional de la Constitución" ${ }^{21}$.

Es por lo anterior, y como se verá más adelante, que la Constitución debe permanecer abierta, de manera continua, a la renegociación democrática ${ }^{22}$. Ello implica, entonces, reconceptualizar el momento constituyente como un momento de transformación revolucionario, un proyecto terminado, una etapa final, pasando a considerarla como una etapa más dentro de un largo proceso evolutivo de definiciones colectivas ${ }^{23}$.

\subsubsection{Contenido de la Constitución minimalista}

La Constitución minimalista no debe ser confundida con una Constitución que promueve un Estado mínimo, típicamente asociado a Nozick ${ }^{24}$. El sentido de un enfoque como el minimalista dice relación, si seguimos ahora a Jeremy Webber, con la idea de una

ción (Israel, India e Irlanda) representan tres diferentes modelos de estrategias constitucionales que pueden ser incluidas en la caja de herramientas incrementalista: posponer la redacción del texto constitucional (Israel), la adopción de fórmulas ambiguas dentro de la Constitución (India) y el establecimiento de cláusulas y declaraciones en conflicto (Irlanda). LeRner (2013) p. 11.

18 WebBer (2009) p. 13.

19 Webber (2009) p. 30. Para el autor, un buen ejemplo se encuentra en el hecho de que existan constituciones -como la de India-, que dicen tener una "estructura básica" que no puede ser reformada y otras constituciones -como la Ley Fundamental de la República Federal Alemana- posee una "cláusula pétrea” que hace "inadmisible" ciertas modificaciones". WebBer (2009) p. 30.

20 Lerner (2013) p. 42.

21 WebBer (2009) p. 30

22 Webber (2009) p. 34

23 Lerner (2013) p. 39.

24 Ver Nozick (1977). 
Constitución "delgada". Enfatizando el rol modesto de la Constitución, Webber no solo invita a tener una actitud constitucional reticente ante la consolidación de los valores y creencias aparentemente comunes, sino a enfocarse en los procesos más que en lo sustantivo. En efecto, una sociedad para Webber, no tiene por qué estar de acuerdo con los mismos valores, sin embargo sí es posible acordar un proceso para resolver las diferencias ${ }^{25}$.

Para Sunstein las constituciones pueden ser vistas, como estrategias de precompromiso $^{26}$, esto es, los ciudadanos se comprometen a sí mismos, de forma previa a ingresar al pacto social, a seguir ciertos cursos de acción. Esta visión captura uno de los objetivos centrales del constitucionalismo: asegurar las condiciones para una democracia pacífica y de largo funcionamiento que debe enfrentar diferencias sociales persistentes y el pluralismo religioso, étnico, cultural, etc. ${ }^{27}$.

Sobre la base de lo anterior, el autor sostiene que la consagración de ciertos derechos y arreglos constitucionales puede obedecer a los siguientes objetivos: (i) algunos derechos pueden ser consagrados debido a la creencia de que en algún sentido son pre o extrapolíticos, esto es, a los individuos les debiese estar permitido ejercerlos con independencia a la opinión de la mayoría; (ii) muchos de los derechos que son consagrados constitucionalmente derivan del principio democrático en sí mismo, y su protección contra procesos mayoritarios deriva de las premisas de la democracia y no crea tensión con el ideal del autogobierno a través de la política; (iii) los arreglos institucionales pueden también ser entendidos como un esfuerzo de proteger esferas privadas de la regla de mayoría; (iv) las reglas estructurales (orgánicas/procedimentales) limitan el poder político de la mayoría de hoy (o de la minoría) y en este sentido crean dificultades para aquellos que creen que el único propósito del constitucionalismo es crear el marco para la gobernanza democrática, sin embargo, si estas reglas son asumidas como estrategias de precompromiso, se infiere que algunas de ellas serán tanto habilitantes como restrictivas; (v) las cláusulas constitucionales pueden sacar algunos temas de la agenda política ordinaria para fortalecer el proceso político mismo; (vi) hay reglas que están diseñadas -en orden a ser facilitadoras del proceso democrático- para resolver problemas de acción colectiva, esto es, situaciones en las que la persecución del interés individual por cada uno produce resultados que son destructivos respecto de toda la comunidad, y que pueden ser evitados si todos los actores acuerdan, adelantadamente, a la coerción para asegurar la cooperación; (vii) existen reglas que aseguran que los representantes sigan las decisiones razonadas del pueblo más que sus pasiones momentáneas; y (viii) hay mecanismos constitucionales que aseguran una deliberación y discusión orientada al acuerdo sobre el bien común, más que al faccionalismo y a los acuerdos en el interés propio ${ }^{28}$.

Así, las constituciones, al menos en su versión minimalista, buscan establecer un piso institucional mínimo compartido, sobre la base de arreglos institucionales predominantemente orgánicos y procedimentales que, separando adecuadamente y limitando los poderes

\footnotetext{
25 Ver Webber (2000).

26 Tesis que se atribuye a ELSTER (1989), aunque posteriormente revisaría críticamente esta en ELSTER (2002).

27 SunSTEIN (2001) p. 97.

28 Sunstein (2001) pp. 97-101.
} 
públicos (generando un equilibrio virtuoso entre habilitación y restricción al poder público), se establezcan reglas políticas básicas que permitan al proceso democrático tomar el grueso de las decisiones de la vida social. Y precisamente porque también se busca proteger derechos y libertades anteriores al pacto social y al proceso democrático es que se garantizan ciertos derechos civiles y políticos, los básicos.

¿Deben las constituciones proteger los derechos económicos y sociales? Para Sunstein, es ciertamente relevante que si las necesidades básicas no están cubiertas, las personas no pueden realmente disfrutar del estatus de ciudadano: "Un derecho a garantías mínimas económicas y sociales puede estar justificado, no solo sobre la base de que las personas bajo condiciones desesperadas no tendrán buenas vidas sino porque la democracia requiere de cierta independencia y seguridades para todos" ${ }^{29}$. Pero existen una serie de complejidades en este ámbito a juicio del autor: "Un Estado puede intentar enfrentar las necesidades de las personas en múltiples formas, tal vez creando incentivos para que las personas se ayuden a sí mismas, más que acudiendo al Estado" ${ }^{0}$. Tal vez "no exista la necesidad de contar con protecciones constitucionales en este espacio; tal vez este es un tema que pueda ser resuelto democráticamente" ${ }^{1}$. En cualquier caso para él, "las garantías económicas y sociales amenazan con poner a las cortes en un rol para el cual no están preparadas adecuadamente" 32 . Más aún, para Sunstein, mientras las constituciones modernas tienden a proteger tales garantías, podemos entender la opinión que sostiene que, en algunos países, crearían más problemas que beneficios ${ }^{33}$, pudiendo transformarlas en poco más que un pedazo de papel de nulo valor ${ }^{34}$.

Por otra parte, ¿qué espacio debe ocupar institucionalmente la revisión judicial de la legislación (control de constitucionalidad de la ley)? Sunstein viene promoviendo desde hace algo más de una década una aproximación que sea deferente con el proceso democrático, sin dejar de lado el rol eminentemente contramayoritario que juega la Judicatura en este ámbito ${ }^{35}$, alejándose entonces de planteamientos más críticos como los de Tushnet $^{36} \mathrm{o}$ Waldron $^{37}$. En Chile, los planteamientos del minimalismo judicial han sido favorablemente recogidos, por ejemplo, en los trabajos de García y Verdugo ${ }^{38}$, y Contesse ${ }^{39}$. También podría incluirse a Correa ${ }^{40}$.

\footnotetext{
29 SunSTEIN (2001) p. 235.

30 SunSTEIN (2001) p. 236.

31 SunSTEIN (2001) p. 236.

32 SunSTEIN (2001) p. 236.

33 SunSTEIN (2001) p. 236.

34 Sunstein (1993) p. 36.

35 Ver especialmente Sunstein (2001a). Ver también, desarrollos posteriores en SunsteIn (2005), (2006), (2007) y (2009).

36 Ver Tushnet (1999). Ver también Tushnet (2008), considerando formas de revisión judicial débil para garantizar de derechos sociales.

37 Ver Waldron (1999). Posteriormente, reevaluaría algunos de sus planteamientos en Waldron (2006).

38 Ver García y Verdugo (2013).

39 Ver CONTESSE (2008).

40 Ver Correa (2013).
} 
En este sentido, para el autor, no solo el proceso político debe tomar las decisiones más importantes (y que son por definición las que nos dividen con mayor frecuencia), sino que los jueces deben promover en su labor en la revisión judicial tanto la deliberación política (reflexión, entrega de razones y la negociación en el proceso político), como el accountability (rendición de cuentas por parte de los electores a los actores del proceso político) ${ }^{41}$. Este enfoque le permite además al proceso político ampliar su espacio para adaptarse a los desarrollos futuros, permitiendo el que se vaya agregando nueva información y perspectivas a la controversia en cuestión ${ }^{42}$. En efecto, decisiones amplias, tempranas, pueden tener efectos sistémicos desafortunados: pueden prevenir el tipo de evolución, adaptación y negociación argumentativa que tiende a acompañar la reforma social duradera ${ }^{43}$, pudiendo impedir la deliberación social, la negociación, el aprendizaje, y la evolución moral en el tiempo ${ }^{44}$.

\subsection{Minimalismo y CAmbio CONSTitucional (inCREMENTAlismo)}

Para Levmore, un crítico del incrementalismo, es fácil incentivar a los abogados a ser moderados, o incrementalistas. El caso a favor del incrementalismo -cambios legales que pueden permitir puntos de detención experimental que no necesariamente implican un movimiento a lo largo de una pendiente resbaladiza (slippery slope) - se construye sobre la base de argumentos sobre consecuencias no intencionadas, expectativas, aversión al riesgo, y aprender haciendo ${ }^{45}$. Asimismo, un argumento obvio e importante a favor del cambio incremental, sea por ley, decisión judicial o regulación, es que frecuentemente aprendemos de la experiencia, siendo el beneficio esperado el que el diseño del segundo paso sea reflejo de las lecciones aprendidas con el primero ${ }^{46}$. Mientras tanto, cualquier propuesta a favor de un cambio de gran envergadura, es asumida "como el producto de la impaciencia y de una apreciación inadecuada de la historia y el precedente" ${ }^{47}$. Los incrementalistas favorecen saltos en vez de pequeños pasos solo cuando los sistemas se consideran irreparables o los malos hábitos deben ser terminados de raíz en vez de pequeños empujones (nudges) ${ }^{48}$. Dado que una serie de actores institucionales (las legislaturas, las cortes, los funcionarios de la administración, las agencias, etc.) e incluso los electores interactúan, para Levmore, la creación normativa incremental frecuentemente es la estrategia que mayor respeto tiene del rol de cada jugador ${ }^{49}$, y puede superar la oposición política ${ }^{50}$.

Si volvemos al debate entre Jefferson y Madison que se analizó al comenzar este artículo, que, tradicionalmente sostiene Sunstein, se ha estimado ganó el segundo, en realidad es posible pensar que el primero obtuvo su revancha: "El cambio constitucional ha

\footnotetext{
41 Sunstein (2001a) p. 4.

42 Sunstein (2001a) p. 53.

43 Sunstein (2001a) p. 27.

44 Sunstein (2001a) p. 59.

45 LeVMore (2010) p. 816.

46 LeVmore (2010) p. 833.

47 Levmore (2010) p. 816.

48 Levmore (2010) p. 816.

49 Levmore (2010) p. 816.

50 Levmore (2010) p. 833.
} 
ocurrido a través de las decisiones de diferentes mentes y generaciones sucesivas, en una forma que captura las esperanzas de Jefferson" 51 . En diversos ámbitos, "el triunfo de Madison es bastante ilusorio. Han existido muchos padres fundadores, y pueden ser encontrados en diferentes generaciones. La nuestra es una Constitución de muchas mentes" ${ }^{2}$. Así, sostiene Sunstein "buena parte del cambio constitucional ha ocurrido siguiendo un proceso incremental, no a través del cambio a gran escala generacional favorecido por Jefferson. Tradiciones que evolucionan, más que quiebres precipitados, son la vía americana usual"53.

Hay cinco aspectos relevantes del minimalismo constitucional en relación al cambio constitucional, esto es, la mirada incrementalista que parece interesante detenerse a examinar con profundidad: (1) el espíritu burkeano frente al cambio constitucional, gradual, y escéptico del cambio radical (y de sus promotores); (2) la renegociación constitucional, reflejo de que el proceso constituyente es uno continuo y contingente; (3) minimizar la separación entre política constitucional y política ordinaria; (4) el problema de la irreversibilidad (los costos del cambio constitucional); y (5) recalcar la particular solemnidad de la reforma constitucional.

\subsubsection{Espíritu Burkeano: incrementalismo y escepticismo ante el cambio radical}

Concordamos con Kronman: si alguien quiere tomarse en serio la cuestión de la tradición constitucional, un lugar de partida evidente es la obra de Edmund Burke, cuyo sentido práctico de la política queda plenamente reflejado en su obra intelectual ${ }^{54}$. Para Ackerman, desde la perspectiva de los defensores del rol de la tradición en el derecho, no hay quien pueda equipararlo en términos contemporáneos ${ }^{55}$.

Las ideas sobre el cambio constitucional de Burke, descansan en sus concepciones acerca de la nación (y la Constitución) como un pacto intergeneracional, y la riqueza que subyace a la evolución constitucional como proceso gradual o incremental ${ }^{56}$.

Hay dos aspectos del pensamiento de Burke que en esta materia parece relevante analizar; su especial valoración por el incrementalismo como fórmula de cambio constitucional; y, su actitud escéptica de las grandes transformaciones a base de abstracciones.

En vez de descansar en la razón o en teorías abstractas, Burke enfatizaba la tradición y la práctica pasada. La práctica pasada ha sido probada. Burke era así un empirista, "prefiriendo la evidencia acerca la efectividad de las políticas más que de las predicciones teóri-

\footnotetext{
51 SUNSTEIN (2001) p. 3.

52 Sunstein (2001) p. 3.

53 Sunstein (2001) p. 6.

54 Kronman (1990) p. 1047.

55 ACKerman (1991) p. 17.

56 Para Burke la sociedad es "ciertamente" un contrato: "Los contratos accesorios concluidos pensando en objetos de mero interés ocasional pueden ser rescindidos a voluntad -pero el Estado no puede considerarse de la misma medida que un pacto de constitución de sociedad que trafica pimienta y café... que pueda ser creada en consideración a un interés temporal de poca importancia y disuelto al arbitrio de las partes-. Hay que considerarlo con otra reverencia, porque no es una asociación (partnership) que se proponga lograr cosas que hacen referencia únicamente a la existencia animal de naturaleza temporal y perecedera... Por lo que hace a los fines de tal asociación, no pueden conseguirse en muchas generaciones y por ello es una asociación no solo entre los vivos, sino entre los vivos, los muertos y los que han de nacer”. BURKE (1996) p. 125.
} 
cas. A Burke le desagradaba el cambio radical, que en su perspectiva se basaba en la razón imperfecta y no en la experiencia" ${ }^{57}$. Burke no rechazaba todo cambio, sin embargo, favorecía el cambio incremental, con cada paso evaluado empíricamente antes de ser tomado el paso siguiente ${ }^{58}$. En efecto, para Burke mediante un progreso lento, pero sostenido, "se vigila el efecto de cada paso; el buen o mal éxito del primero nos ilumina para dar el segundo y así de luz en luz, somos guiados con seguridad a lo largo de toda la serie" 59 .

Para este inglés, conservación y cambio van de la mano, no operan como antónimos. Se trata de una cuestión de la mayor importancia a la hora de intentar caricaturizar el pensamiento de Burke como la simple mantención del statu quo: "Un Estado sin medios de efectuar algún cambio carece de medios propios de conservación. Sin tales medios puede incluso correr el riesgo de perder aquella parte de la Constitución que desea conservar más religiosamente" ${ }^{10}$. En efecto, para Burke, el legado concreto del incrementalismo constitucional entre los británicos es fácilmente identificable ${ }^{61}$. Por lo demás, frente a las críticas de la (baja) velocidad del cambio asociadas a este enfoque, destaca el que para este, los cambios radicales tienen un impacto concreto en la vida de las personas que se verán afectadas por este, sensibilidad que nuestro autor no encuentra en quienes plantean cambios radicales ${ }^{62}$.

Desde la perspectiva del escepticismo burkeano ante el cambio radical y sus promotores, un buen punto de partida, siguiendo a Kronman, es entender que aquellos que se aproximan a los problemas de la vida política bajo el espíritu prudencial recomendado por Burke, son muy deferentes (aunque no por ello acríticos) con las prácticas e instituciones

57 Listokin (2008) p. 487.

58 Listokin (2008) p. 487.

59 Burke (1996) p. 188. Prosigue el autor: "Vemos así que las partes no chocan entre sí ni con el sistema. Los males que hay latentes aun en las medidas más prometedoras se van resolviendo conforme surgen. Se sacrifica lo menos posible una ventaja a las demás. Compensamos, reconciliamos, contrapesamos. Podemos unir en un todo consistente las distintas anomalías y principio contrapuestos que se encuentran en las mentes y en los asuntos de los hombres. Y de ahí surge una excelencia no de simplicidad, sino muy superior; una excelencia de composición”. BURKE (1996) p. 188.

60 Burke (1996) p. 58.

${ }^{61}$ En este sentido, sostiene el autor: "Creo que nuestra feliz situación se debe a nuestra constitución, pero a la totalidad de ella y no a una parte aislada; se debe en gran medida tanto a lo que hemos dejado subsistente en nuestras varias revisiones y reformas, como a lo que hemos alterado o añadido. Nuestro pueblo encontrará suficiente empleo para un espíritu verdaderamente patriótico, libre e independiente, evitando que se viole la Constitución que posee. No quiero con esto excluir la posibilidad de hacer cambios; pero incluso cuando se hacen cambios hay algo que conservar. Debe impulsarme un agravio para proponer un remedio. En lo que hubiere de hacer trataría de seguir el ejemplo de nuestros antepasados. Prefiero hacer la reparación en un estilo que sea lo más aproximado posible al del edificio”. BurKe (1996) pp. 256-257.

62 En este sentido, sostiene Burke “... me podéis objetar: 'Un proceso de este tipo es lento. No es adecuado para una Asamblea que se gloría de realizar en pocos meses la tarea de siglos. Tal modo de reforma exigiría probablemente muchos años'. Sin duda, que podría exigirlos y que debería exigirlos además. Una de las excelencias de un método en el cual el tiempo figura entre los ayudantes es que la actuación es lenta y en algunos casos casi imperceptible. Si la circunspección y la preocupación constituyen parte de la prudencia cuando trabajos sobre materias inanimadas, tiene que ser parte también de nuestra obligación cuando el objeto de nuestra demolición y construcción no lo constituyen el ladrillo y la madera, sino seres sensibles, a los que la alteración repentina de su estado, situación y hábitos, puede hacer desgraciados. Pero parece como si la opinión que prevalece en París fuera la de que un corazón insensible y una confianza sin límites son las únicas cualificaciones del perfecto legislador. Mis ideas acerca de tan alto oficio son muy distintas”. Burke (1996) pp. 187-188. 
políticas existentes. En sus aproximaciones, toman especialmente en consideración las características peculiares, típicamente accidentales, que definen una cultura política particular en la que, accidentalmente, se encuentran ${ }^{63}$. Por el contrario, aquellos que ven los mismos problemas bajo un prisma filosófico, rechazan reconocer las contingencias que son consideradas de manera relevante en las decisiones del político prudente. Insisten, en cambio, en que la política requiere de una aproximación abstracta que ignora la práctica pasada entre los regímenes que han evolucionado históricamente. Para ello estas contingencias no son más que escombros sin mayor trascendencia, y su ideal es ver cada problema con la frescura y la transparencia que pueden ser alcanzadas solo ignorando la basura acumulada del pasado ${ }^{64}$. Para aquellos que poseen esta especial visión, pronto concluirán -nos dice Kronman interpretando a Burke-, que sus poderes de reflexión abstractos son suficientes por sí mismos para alcanzar cualquier dilema imaginable, y resuelven actuar, en todo momento, como si estuvieran fundando sus regímenes desde cero $^{65}$, carte blanche como diría Burke ${ }^{66}$.

Finalmente, no podemos dejar de hacer notar cómo buena parte de los planteamientos centrales de Burke, siguen plenamente vigentes en este debate. Tres ejemplos lo demostrarán. En primer lugar, en la construcción de su tesis dualista, Ackerman junto con realizar críticas al enfoque burkeano -como se observará más abajo-, ha señalado dos aspectos que tienen en común ambas posiciones. Primero, la preocupación por los procesos históricos concretos que han debido enfrentar y solucionar los hombres de Estado (statesmen) ante diversos dilemas que han planteado los momentos de política constitucional ${ }^{67}$. Segundo, la noción de que la Constitución es mejor entendida como una tradición histórica de teoría y práctica constitucional, un lenguaje político que ha ido evolucionando, y que permite a los ciudadanos, de diferentes siglos, ir construyendo una identidad nacional ${ }^{68}$. Ello es contrario al enfoque monista, del cual Ackerman es crítico, que solo reverencia el altar del presente y la regla democrática, lo que solo requiere consultar la última norma aprobada por el Con-

\footnotetext{
63 Kronman (1990) p. 1055.

64 Kronman (1990) p. 1056.

65 Kronman (1990) p. 1056.

${ }_{66}$ Sostiene Burke: "A un hombre que no actúa bajo la influencia de la pasión, que no tiene a la vista en sus proyectos sino el bien público, le saltará inmediatamente a los ojos una gran diferencia entre lo que la política puede aconsejar respecto a la introducción originaria de tales instituciones y el problema de su abolición total una vez que sus raíces han penetrado tan hondo y con tanta extensión y que cosas más valiosas que aquellas están tan adaptadas a ellas por hábitos añejos y ligadas de tal manera con ellas que no se pueden destruir las unas sin poner en grave peligro las otras. Si el problema fuese realmente tal como en su despreciable modo de argumentar lo presentan los sofistas, su posición podría ser embarazosa, pero en esto como en todas las cuestiones políticas hay un término medio. Hay algo más que la mera alternativa entre la destrucción total y la subsistencia sin reformas... No puedo concebir cómo un hombre puede llegar a una presunción tal que le permita considerar a su país como nada más que una carte blanche, en la que puede dibujar lo que se le antoje. Un hombre lleno de buenas intenciones, ardiente y especulativo, puede desear que la sociedad a que pertenece esté constituida de modo distinto a como él la encuentra; pero un buen patriota y un verdadero político piensa siempre en la manera de conseguir mejor resultado con los materiales de que dispone. Mi tipo ideal de hombre de Estado reúne una tendencia a conservar y una capacidad para mejorar. Cualquier otra cosa es vulgar en la concepción y peligrosa en la ejecución”. Burke (1996) pp. 177-178.

67 ACKerman (1991) p. 22.

68 Ackerman (1991) p. 22.
} 
greso $^{69}$. Para Ackerman lo relevante es situar la conversación constitucional en una entre diversas generaciones ${ }^{70}$.

Por otra parte, Sunstein ha construido su visión del minimalismo sobre la base de examinar críticamente la obra de Burke. En efecto, para él existen dos enfoques minimalistas diferenciables, aunque cuentan con un piso común importante: el tradicionalista-asociado al pensamiento de Edmund Burke- y el racionalista. A ambos le gustan las decisiones limitadas y modestas. Desprecian las revoluciones. Ambas formas de minimalismo "insisten en pequeños pasos en vez de terremotos" y "sospechan de los visionarios" un lado, los minimalistas burkeanos tratan de construir sobre las prácticas del pasado, partiendo de la base de que las "muchas mentes" que contribuyeron a generar tales prácticas, las pensaron muy bien ${ }^{72}$; por otro, sostiene Sunstein, algunos minimalistas, aunque desprecian las revoluciones, rechazan el burkeanismo en favor del racionalismo: "Cuestionan las tradiciones. Están completamente dispuestos a preguntarse acerca de si prácticas de larga data están basadas realmente en la razón y en la buena fe, o, en cambio, en el sin sentido y el prejuicio"73. No deja de ser interesante mencionar que para el autor, los minimalistas burkeanos son críticos con el originalismo ${ }^{74}$.

Asimismo, destaca el que, tras más de dos siglos, el enfoque sobre la evolución constitucional siga con tanta fuerza en el debate británico. Ello se ve respecto de si avanzar o no hacia una Constitución escrita (codificada). Como han sostenido recientemente Jowell y Oliver: un argumento "fuerte" en contra de ello [codificar] es que "inhibiría el tipo de evolución que hemos visto en este país en respuesta al cambio de circunstancias, necesidades y expectativas. Tampoco resultaría fácil llegar a acuerdo respecto del contenido de la constitución escrita bajo una situación en la que no existe necesidad alguna de romper abruptamente con el pasado"75.

\subsubsection{La negociación constitucional es continua y contingente}

Para Gregoire Webber, lo contrario a la concepción de la Constitución como etapa final o un proyecto completamente terminado, es la idea de la Constitución como "actividad”. Ello implica que la Constitución debe permanecer abierta, de manera continua, a

\footnotetext{
69 ACKerman (1991) p. 23.

70 Ackerman (1991) p. 23.

71 SUNSTEIN (2009) p. 36.

72 SUNSTEIN (2009) p. 10.

73 Sunstein (2009) p. 10.

74 En este sentido, para el autor, los minimalistas burkeanos tienen poco interés en el originalismo: "Desde la perspectiva burkeana, el originalismo es demasiado radical, debido a que exige movimientos radicales en el derecho; es inaceptable precisamente por esa razón. Los minimalistas burkeanos aprecian la estabilidad. Están completamente dispuestos a aceptar las decisiones que no responden al entendimiento originalista cuando la decisión de derogarlas atenta contra las prácticas establecidas. Los minimalistas burkeanos atesoran nuestras tradiciones constitucionales, extendidas por décadas e incluso siglos, y ven dichas tradiciones como el producto no de un momento particularmente reconocible, sino que la suma de decisiones de muchos actores... A los minimalistas burkeanos, el originalismo les parece incómodamente cercano a la Revolución Francesa, buscando echar por la borda tradiciones arraigadas sobre la base de una teoría abstracta”. Sunstein (2001) pp. 38-39.

75 Jowell y Oliver (2011) pp. 5-6.
} 
la renegociación democrática ${ }^{76}$. En un sentido similar se pronuncia Bellamy, para quien, debido a que los desacuerdos que la gente mantiene sobre la justicia política son poco manejables y a que se modifican conforme sus ideales y preocupaciones cambian según se van adaptando las circunstancias, "el proceso constituyente necesita ser entendido como un proceso político continuo"77. Ello sugiere que los ciudadanos han de tener siempre la capacidad de discutir y reconstruir las reglas del juego democrático ${ }^{78}$, lo que es posible a través de la reforma constitucional.

En este sentido, y volviendo a Webber, "a pesar de las vendas y la amnesia histórica que afecta a aquellos que miran a una constitución como una declaración definitiva acerca de lo que es requerido para asegurar la legitimidad política del Estado"79, no se puede concluir que la existencia de una Constitución ha agotado la búsqueda de los arreglos constitucionales que serán exitosos en asegurar la legitimidad política. Las contingencias históricas de todos los momentos de creación constitucional deben llevar a ver los cierres de las negociaciones constitucionales como contingentes. La práctica política tiende a confirmar esto, dado que los debates en torno a renegociaciones constitucionales raramente quedan fueras de la agenda política ${ }^{80}$.

Así, las circunstancias que rodean muchas de las negociaciones constitucionales sugieren que "cualquier acto de creación constitucional será el producto del razonamiento falible de ciudadanos llevado a cabo en un momento histórico dado y bajo los supuestos que acompañaron tal época de la historia" ${ }^{\prime 1}$. Para Webber, ello invita a examinar los llamados a la renegociación constitucional, esto es, "las razones que trascienden la contingencia histórica que llevan a desafiar [la constitución vigente], y, asimismo, reevaluar si la Constitución está logrando la conciliación afirmada acerca de los principios de la legitimidad política [principios democráticos y de derechos humanos]"82.

Webber identifica seis principios sobre los cuales se basa la renegociación constitucional $^{83}$. Los primeros cuatro (la igual importancia de los principios democráticos y de derechos humanos; la indeterminación en la forma de actualizar ambos principios; la ausencia de un criterio de exactitud para medir cómo asegurar la legitimidad política del Estado, una vez descartados extremos como el establecimiento de la esclavitud o la prohibición de elecciones de autoridades; y la permanencia de desacuerdos), resaltan la actitud de humildad que debe acompañar el término de toda negociación constitucional. "Ellos hablan acerca de la necesidad de estar conscientes que todo término a una negociación constitucional es tentativa, lo que no quiere decir que no merezca el respeto que merece un logro como aquel" ${ }^{84}$. Los últimos dos principios (el cambio de circunstancias de lo estatal y

\footnotetext{
76 Webber (2009) p. 34.

77 Bellamy (2010) p. 123.

78 Bellamy (2010) p. 123.

79 Webber (2009) p. 34.

${ }^{80}$ Webber (2009) p. 34.

81 Webber (2009) p. 34.

82 Webber (2009) p. 34.

83 Webber (2009) pp. 34-41.

84 Webber (2009) p. 34.
} 
el respeto al principio democrático), también demuestran, en particular este último, la importancia de estar abiertos a la renegociación constitucional. En efecto, la idea de una renegociación continua sensible al principio democrático, se opone a "nunca", "procedimiento especial" y "en intervalos fijos" ${ }^{\text {" }}$.

Finalmente, y analizando cuatro posibles enfoques de cambio constitucional -la revolución, esto es, el rechazo a las reglas y procedimientos constitucionales, a las autoridades establecidas y apelar directamente al poder constituyente originario; la reforma constitucional; las cláusulas derogatorias (notwithstanding clause); y el constitucionalismo viviente, mediante la actualización de la Constitución a través de la interpretación judicial-, para Webber solo el segundo y el cuarto son modelos de renegociación constitucional continua. Sin embargo, cuando el cambio proviene en este último caso desde la Judicatura, se trata de una renegociación no democrática ${ }^{86}$.

\subsubsection{Minimizar distinción entre política constitucional y ordinaria}

En la introducción se han descrito brevemente los elementos centrales de la teoría dualista de Ackerman. En ella se establece la distinción entre las decisiones que son tomadas en las excepcionales fases de política constitucional, y aquellas, comunes, en las de la política ordinaria. Como se verá, para la aproximación minimalista dicha distinción debe ser minimizada.

Sunstein, examinando la tesis de Ackerman, sostiene que el cambio constitucional "no es solamente el producto de "momentos" en que los ciudadanos se movilizan a favor de reformas a gran escala. Existe un continuo desde cambios pequeños generados en periodos de relativa estabilidad, a cambios mayores, que se han producido frente a crisis o el llamado de movimientos sociales a un viraje significativo" ${ }^{87}$. Tal como lo esperaba Jefferson, "cada generación genera un grado de reforma constitucional, y lo hace debido a un nuevo entendimiento sobre lo fáctico o nuevos juicios de valor" 88 .

En otro trabajo de Sunstein, junto a Holmes, sostienen que derrumbar (collapse) la distinción entre política constitucional y política ordinaria posee la ventaja de proveer una oportunidad a la nación política de ser introducida, en el tiempo, a las grandes cuestiones sobre el sistema constitucional (presidencialismos versus parlamentarismo, representación proporcional versus de distrito único, unicameralismo versus bicameralismo, supremacía legislativa versus revisión judicial, entre otros), mientras tales tópicos son debatidos seriamente ${ }^{89}$.

\footnotetext{
85 Webber (2009) pp. 41-42. Para Webber, la idea de "nunca" se puede asociar a la visión de la Constitución como estado final, presente, por ejemplo en Rawls; "procedimiento especial" a la distinción entre momentos de política constitucional y política ordinaria de Ackerman; e "intervalos fijos", reflejada en la tesis jeffersoniana de entrar en un estado de creación constitucional cada 19 años, con el agravante de que los ciudadanos no serían libres, en el período intermedio, para renegociar la Constitución.

86 Webber (2009) p. 47.

87 SunStein (2001) pp. 5-6.

88 SUNSTEIN (2001) pp. 6.

89 Holmes y Sunstein (1995) p. 277.
} 
Para Lerner, una de las estrategias constitucionales inteligentes que se encuentra en la caja de herramientas incrementalista, consiste precisamente en transferir decisiones desde la esfera constitucional a la política (ordinaria): "Reconociendo que las decisiones sobre temas controversiales de una sociedad requieren de un debate público y político extenso, la estrategia incrementalista canaliza este debate a través de la arena política ordinaria en el Congreso" ${ }^{\circ 0}$. Así, temas controversiales son entonces transferidos desde la esfera constitucional de creación normativa "superior" a la esfera política de creación normativa "ordinaria”, si utilizamos la distinción de Ackerman. Dicha transferencia está basada en el supuesto que "el dominio de la legislación ordinaria permite mayor flexibilidad para acomodar las demandas desde las diversas posiciones, y más espacio para soluciones innovadoras y matizadas para tensiones complejas" ${ }^{11}$ y puede ser "percibido como más compatible con la compresión evolutiva de la Constitución"92.

La idea de minimizar la distinción examinada, sin terminarla o eliminarla por completo parece relevante en la medida en que las reglas orgánicas y procedimentales que regulan la política básica, no sean objeto permanente de intentos de revisión y transformación completa, práctica continua en el constitucionalismo latinoamericano ${ }^{93}$. Así, por ejemplo, una vez que la discusión constitucional en Chile derive en un cambio o reemplazo del régimen político y/o del sistema electoral parlamentario, debiese existir un cierto ánimo de permanencia del núcleo de estas, sin perjuicio, obviamente, de ir evaluando e introduciendo los perfeccionamientos necesarios a la luz de los déficits que se vayan detectando y la evidencia.

\subsubsection{El problema de la irreversibilidad (costos del cambio)}

Una de las preocupaciones más relevantes para los minimalistas dice relación con el costo de los grandes cambios, lo que también se ha llamado el problema de la irreversibilidad ${ }^{94}$.

Para Listokin, algunos de los aspectos de todo cambio legal como los costos de información y de aprender sobre un tema o su implementación son siempre irreversibles, pero ello no implica que el cambio legal específico como un todo lo sea. En cambio, un cambio legal es irreversible si en sí mismo o una parte relevante de sus efectos no pueden ser anulados ${ }^{95}$.

Debido a que los costos de transacción involucrados en el cambio constitucional son extremadamente altos, sujetos además, por lo general, a supermayorías, para los minimalistas, los cambios irreversibles debiesen ser pospuestos en orden a obtener toda la evidencia respecto de los mismos antes de implementarla, en particular porque la supermayoría hace difícil modificar una reforma fallida ${ }^{96}$.

\footnotetext{
90 LeRner (2013) p. 45.

91 LERNER (2013) p. 45.

92 LERNER (2013) p. 45.

93 Ver SCHOR (2006).

94 Ver, por ejemplo, Sunstein (2006a) y LEVMOre (2010).

95 Listokin (2008) p. 522. Sunstein (2006a) distingue dos tipos de irreversibilidades relevantes: aquellas que son graves (seriousness) de aquellas que son costo hundido (sunk costs).

96 Listokin (2008) p. 530.
} 
Para Holmes y Sunstein, por su parte, todo lo que debe saber un electorado democrático para resistir cada impulso caprichoso de "mejorar" la Constitución es que todas las reglas tienen defectos y consecuencias negativas colaterales, y que los costos del cambio pueden ser mayores que los beneficios: "Si las reglas del juego están funcionando razonablemente bien, esto es todo lo que debe decirse para prevenir interminables manipulaciones al marco constitucional" 97 . Por el contrario, para los autores, no hay que apelar a una "vía superior de creación de normas jurídicas", implícitas en la Constitución, reservadas para el "yo superior" de la nación y cabalgando por encima de la baja política, de creación ordinaria de normas ${ }^{98}$.

\subsubsection{Especial solemnidad de la reforma constitucional}

Finalmente, y en un contexto como el debate constitucional chileno actual que ha trivializado el sentido profundo de la reforma constitucional, existen una serie de aspectos vinculados a esta, que reflejan su especial solemnidad y sentido político.

George Washington, sostuvo que: "El pueblo (porque será de este juzgar) puede, dado que tendrá la ventaja de la experiencia de su lado, decidir con igual propiedad, las modificaciones y reformas que sean necesarias... En efecto, no creo que estemos más inspirados, tengamos mayor sabiduría, o poseamos mayor virtud, que la que tendrán los que vengan después" ${ }^{\prime}$. En este sentido, Holmes y Sunstein, sostienen que la reforma constitucional provee una vía a los redactores de compartir parte de su autoridad sobre la Constitución con las generaciones siguientes ${ }^{100}$. Más radical es el destacado historiador Gordon Wood, para quien la noción misma del proceso de reforma puede ser descrita como "la institucionalización y legitimación de la revolución" ${ }^{\prime 01}$.

Por lo demás, no hay que olvidarse, como sostiene Amar, que las reformas constitucionales no son solo palabras, sino compromisos colectivos de las actuales generaciones por redimir los pecados originales de la generación pasada ${ }^{102}$.

Otra perspectiva interesante dice relación con la naturaleza de la reforma. Para Holmes y Sunstein, las categorías desarrolladas por Sieyes en torno al poder constituyente, no han sido exitosas en explicar la naturaleza del poder de reforma: "Habita una dimensión desconocida entre poderes autorizantes y autorizados... El poder de reforma es simultáneamente creador y creado, regulador y regulado, original y derivado, superior e inferior a la Constitución" 103 . Este patrón ambos/y "nos alerta acerca del poco teorizado dilema que presenta el poder constitucionalmente regulado de revisar las regulaciones constitucionales del poder" ${ }^{104}$.

\footnotetext{
97 Holmes y Sunstein (1995) p. 304.

98 Holmes y Sunstein (1995) p. 304.

99 Citada en Levinson (1995) p. 3.

100 Holmes y Sunstein (1995) p. 276.

101 Citado en Levinson (1995) p. 4.

102 Amar (2005) p. 18.

103 Holmes y Sunstein (1995) p. 276.

104 Holmes y Sunstein (1995) p. 276.
} 
Para Levinson es fundamental la distinción existente entre interpretación (que posee la capacidad de actualizar la Constitución) y reforma: "La primera [interpretación] es, casi por definición, ordinaria; la segunda [reforma] significa algo fuera de lo ordinario, algo verdaderamente nuevo" ${ }^{105}$. Probablemente la forma más simple de conceptualizar lo que entendemos por reforma es describirla, sostiene Levinson, "como una invención jurídica no derivable del cuerpo de materiales legales aceptados existente" ${ }^{106}$.

\subsection{SÍNTESIS}

Como se ha podido observar, es posible sistematizar una aproximación minimalista e incrementalista a la Constitución y al cambio constitucional. Se trata de una aproximación modesta que descansa en nociones pragmáticas acerca del sentido profundo de la Constitución como pacto social, pero entendiendo las limitaciones de dicha empresa. Por lo mismo, la Constitución no busca ni pretende zanjar las controversias sociales fundamentales, a pesar de lo cual, no evade estas y elabora estrategias para abordarlas y encaminarlas. Tampoco es la Constitución un proyecto acabado, un estado o etapa final, sino una actividad. Es un proceso político continuo, al que concurren diversas generaciones a su construcción. Su contenido está marcado por arreglos institucionales predominantemente orgánicos y procedimentales, los cuales por sí mismo, no solamente son habilitantes para la actuación de los órganos públicos, sino que, e igualmente importante, los limitan, garantizando los derechos y libertades individuales. Lo anterior no obsta a reconocer explícitamente derechos civiles y políticos básicos, pero no parece sensato tener la misma regla respecto de los derechos económicos y sociales, los cuales, deben quedar entregados al proceso político. Lo anterior es especialmente relevante a la hora de pensar el rol de la revisión judicial-control de constitucionalidad de la ley- en particular y el rol de los jueces en general; el minimalismo judicial aconseja a estos ser extraordinariamente deferentes con el proceso político y evitar transformar la Judicatura en el foro donde se resuelven las controversias fundamentales que separan a los ciudadanos. Para ello está el foro democrático.

Esta mirada minimalista, desde una perspectiva sustantiva, tiene también un correlato en cuanto a las formas, particularmente respecto a la manera de entender el cambio constitucional. Así, confluyen en este ámbito diversas aproximaciones que fijan un ethos común. Destacan un cierto espíritu burkeano que privilegia el gradualismo, y mantener una actitud escéptica no solo frente al cambio radical, sino a su promoción desde una perspectiva puramente abstracta y teórica, desatendiendo los elementos particulares presentes en una determinada sociedad y a la luz de una tradición -instituciones, prácticas, etc.- que ha evolucionado sobre la base del aporte y experiencia de múltiples generaciones. Obviamente una versión moderna del minimalismo, rescatando la actitud burkeana, debe ser crítica y rigurosa a la hora de examinar las tradiciones (y sus concreciones en cuanto arreglo constitucional), modificándolas o reemplazándolas cuando corresponda. Asimismo, el que la Constitución no sea un proyecto acabado, un estado final, sino, por el contrario, una actividad,

105 LeVINSON (1995) pp. 15-16. Para Levinson "nuevo", en este contexto, no debe ser confundido con transformativo. Lo primero es asunto de teoría interpretativa; lo segundo, una evaluación del significado de cualquier cambio. 106 LEVINSON (1995) pp. 15-16. 
implica que esta esté de manera permanente abierta a la renegociación constitucional, siendo entonces el proceso constituyente uno continuo y contingente. Para ello es relevante minimizar la distinción entre política constitucional (momento constitucional, intervalos fijos o periodos de discusión constitucional) y política ordinaria. También preocupa al minimalismo los costos del cambio, especialmente cuando es radical y, por tanto, irreversible. Ello es particularmente relevante a la hora de discutir el cambio constitucional, donde los requerimientos de supermayorías hacen particularmente costoso deshacer los cambios que han resultado fallidos. Finalmente, una aproximación como la expuesta, recalca la particular solemnidad de la reforma constitucional.

Se trata de un enfoque que no ha estado exento de críticas. Sabel y Simon, por ejemplo, ponen de relieve que, si bien el minimalismo ha sido influyente en la academia legal y en el discurso de política, ha tenido poco impacto en el diseño institucional ${ }^{107}$, a diferencia de un enfoque vinculado a este: el experimentalismo ${ }^{108}$. Ackerman, por su parte, ha criticado los elementos elitistas presentas en esta ${ }^{109}$. Para Fiss, si bien el minimalismo ha sido defendido sobre la base de que avanza los valores democráticos, dicha visión, en realidad, reduce la democracia al mayoritanismo en oposición a un proceso deliberativo amplio que entrega contenido a los valores fundamentales de la nación y pasa por alto el rol importante y constructivo de la Judicatura en tal proceso ${ }^{110}$. Fiss critica en particular el minimalismo judicial ${ }^{111}$. Vermeule critica la argumentación que subyace la tesis de la Constitución de "muchas mentes"112. Para Levmore, desde la vereda del Public Choice ${ }^{113}$, el incrementalismo ha adquirido una reputación desmedidamente positiva ${ }^{114} \mathrm{y}$ pone poca atención a los grupos de interés, dado que este enfoque "reorganiza la constelación de partidarios y detractores de cambios más profundos y entrega a los grupos de interés razones para realinearse en respuesta al cambio incremental"115.

107 "El Minimalismo ha sido influyente en la academia jurídica y en el discurso público de las políticas, pero su impacto en diseño real de políticas ha sido sorprendentemente limitado. El Presidente Obama frecuentemente invocó ideas minimalistas en su campaña, y nombró a Cass Sunstein, un ícono del minimalismo, como Administrador de la Oficina de Información y Asuntos Regulatorios de la Casa Blanca". SABEL y Simon (2011) p. 55.

108 El experimentalismo puede ser resumido así: "Más que mirar la generación de políticas como un ejercicio de intento único (one-shot), donde el objetivo es adoptar la solución óptima basada en la información disponible, debemos pensar mejor en un proceso continuo de aprendizaje y experimentación". Ver FARBER (1994) p. 791. Ver también. Dorf y SABel (1998).

109 ACKerman (1991) pp. 19-21.

110 Fiss (2008) p. 643.

111 FISS (2008) pp. 647-648.

112 Para el autor, se trata de un género internamente heterogéneo y contiene muchas especies, incluyendo argumentos acerca de cómo las instituciones políticas y legales agregan información, análisis evolucionario de dichas instituciones, afirmaciones acerca de los beneficios de la tradición como fuente de derecho, y análisis sobre las virtudes y vicios de la deliberación. Vermeule (2009) p. 2.

113 Para una introducción sobre esta escuela y su vinculación al derecho constitucional ver GARCía (2008) y García y Soto (2009).

114 LeVMore (2010) p. 857

115 LeVmore (2010) p. 817. En particular, la estrategia incrementalista puede ser utilizada para "dividir y conquistar” grupos. Puede entonces empujar una regulación más allá del óptimo social o tal vez regular las actividades “equivocadas" más que el que sean muchas". Levmore (2010) p. 850. 
Desde el propio incrementalismo también se advierten falencias. Para Lerner, primero, la estrategia incremental puede llevar a hacer concesiones en materia de derechos fundamentales, la potencial sobrerrigidez del acuerdo constitucional material que evolucionó ante la ausencia de una decisión constitucional formal, y el riesgo de polarización interinstitucional entre el Poder Legislativo y la Judicatura ${ }^{116}$. Segundo, el que la transferencia de las cuestiones fundamentales controversiales desde lo constitucional a la esfera política provea mayor flexibilidad es discutible: "La postergación de las decisiones controversiales pueden permitir el surgimiento de arreglos constitucionales materiales, no escritos, que en la práctica pueden convertirse en más rígidos que uno formal, dado que no tienen un mecanismo formal de reforma"117.

\section{LINEAMIENTOS MINIMALISTAS ANTE EL "MOMENTO CONSTITUCIONAL" CHILENO}

El "momento constitucional" chileno ha generado posiciones diversas entre los ius publicistas nacionales. Desde la perspectiva progresista, se encuentra a autores moderados, que abogan por reformas profundas a la Constitución actual (pudiendo o no derivarse de ellas una nueva Constitución) ${ }^{118}$; los que sostienen que el insalvable origen ilegítimo de la Constitución demanda una nueva por la vía de una reforma con epicentro en el Congreso Nacional ${ }^{119}$; hasta los maximalistas, que han sostenido que dado que hoy tenemos una Constitución "tramposa" el camino de una nueva Constitución requiere de una Asamblea Constituyente, pues producto y proceso son indisolubles ${ }^{120}$. También es posible encontrar, en la vereda opuesta, conservadores maximalistas - defensores del originalismo y del statu quo ${ }^{121}$.

Todo maximalismo en este debate -sea progresista como conservador- son contrarios a una sensata evolución constitucional; son acercamientos al debate constitucional desde una visión que divide a la comunidad política, precisamente cuando la Carta Fundamental cumple aquel rol elemental de unir en la diversidad ${ }^{122}$. Ambos pretenden congelar

\footnotetext{
116 LERNER (2013) p. 12

117 LERNER (2013) p. 45.

118 Ver, por ejemplo, ZaPATA (2014). Incluyo en este grupo también a un moderado y minimalista: CorREA (2013).

119 Ver, por ejemplo, Ruiz-TAgLe (2008) y ZuÑiga (2009) y (2013), en este último, en todo caso, abriéndose a la posibilidad de una Asamblea Constituyente como alternativa. También esta última es la posición de FERNÁNDEZ (2013), quien, en todo caso, centra el problema constitucional no en la organización jurídica del poder político, sino en la precariedad de los derechos fundamentales de las personas. Ver también Couso y CoDDOU (2010), quienes sostienen que el proceso debe ser llevado a cabo con mayores niveles de participación y deliberación pública.

120 Ver Atria (2010), (2013) y (2014). Ver también Garretón (2010), Muñoz (2013) y Urquieta (2014).

121 Ver, por ejemplo, Rojas (2013) y VAN DE Wyngard (2013).

122 Comparto con Zapata el que: “... la experiencia histórica chilena demuestra que los avances democráticos solo se han producido cuando sus impulsores han movilizado a grandes mayorías y han respetado a las minorías. Se trata de momentos en que las distintas familias ideológicas que concurren a nuestra tradición republicana han apostado fuertemente por la unidad. Son momentos, además, en que la conducción política reformista ha tenido la sabiduría de conectarse con la profunda vocación pacífica y legalista del pueblo chileno. A contrario sensu, cada vez que los impulsores de los cambios se han dejado arrastrar por el sectarismo, han querido sosla-
} 
en el tiempo un arreglo institucional: los primeros, buscando consagrar los ideales que encuentran en sus artículos y libros, siendo indiferentes el grado de vinculación que tengan ciertos arreglos propuestos con la tradición constitucional chilena; los segundos, promoviendo el arreglo original, tal cual quedó plasmado bajo categorías propias de la guerra fría. Se trata, por lo demás, de aproximaciones que desprecian los acuerdos constitucionales de 1989 y 2005, y como sostuviera Amar, antes citado, descreen el que las reformas no son solo palabras, sino compromisos profundos de las nuevas generaciones por redimir los pecados de las generaciones anteriores. Se trata esta de una reflexión que es particularmente importante y de profundo sentido político y democrático, dado que reformas incrementales, que van siendo acumulativas en el tiempo, pueden reflejar un orden constitucional sustancialmente diferente al original, pudiendo hacer incluso irreconocible el rostro inicial de una Constitución, lo que sucede con la Constitución actual en relación a la Constitución original de 1980 o en su versión de 1989 de ingreso a la democracia.

¿Cómo salir de una situación con potencial alto de parálisis y división, frente a miradas maximalistas que pueden dejar la discusión sobre el cambio constitucional en un callejón sin salida? La salida minimalista, incrementalista, que valora la evolución constitucional, surge como alternativa constructiva. A continuación, se avanzan ciertos lineamientos respecto de cómo, desde una aproximación minimalista, se puede enfocar la discusión en Chile; se examinarán, brevemente, ciertos elementos de contexto involucrados, para pasar a examinar algunos déficits y controversias constitucionales desde el prisma del minimalismo, intentando entregar ciertas orientaciones para enfrentarlas de manera constructiva.

\subsection{ELEMENTOS COMPLEMENTARIOS}

Existen tres elementos complementarios al desarrollo teórico propuesto en este artículo que parecen de la mayor relevancia -y reflejan, por lo demás, que nuestra discusión no puede darse en el vacío, sobre la base de pura especulación abstracta- a la hora de evaluar el "momento constitucional" chileno: la dimensión histórica del proceso, y el que el debate actual debe estar inserto en un debate mayor acerca de la tradición constitucional chilena -y cuán lejana o no se encuentra la Constitución actual de ella-; cuánta evidencia empírica se tiene a la mano respecto del impacto de determinadas instituciones, y cuánto de la creciente evidencia que ha sido levantada especialmente en la última década por parte del constitucionalismo comparado, respecto de los procesos de cambio constitucional y constituyentes -que hoy impiden adoptar una actitud parroquiana y exclusivamente local para enfrentar el debate-, es posible incorporar a nuestro debate; y, las implicancias y riesgos del denominado "nuevo constitucionalismo latinoamericano" y el proyecto de las democracias radicales, aproximación que ha sido decisiva en varios debates constitucionales en nuestra región ${ }^{123}$.

yar, o defraudar, el cumplimiento de las reglas jurídicas o han creído poder precipitar los cambios por medio de la amenaza o el uso de la fuerza, el resultado ha sido siempre el mismo: una derrota para la tradición republicana. Y un retroceso para Chile”. Zapata (2014) pp. 92-93.

123 Sobresalen como exponentes destacados Viciano y Martínez (2010). Ver también Gargarella y Courtis (2009), Pisarello (2010) y Gargarella (2013). En nuestro país destaca el examen crítico de Couso (2013). También es interesante la obra editada por Nolte y SCHILling-VACAFlor (2012), que contiene una aproxima- 
En este sentido, y en primer lugar, no somos la primera generación de chilenos conflictuada por el debate constitucional ${ }^{124}$. Porque junto con las críticas de Lastarria a la Constitución de 1833 -que bien podrían ser parte de nuestro debate actual ${ }^{125}$-, se encuentra la valoración positiva de un Jorge Huneeus -en su monumental La Constitución ante el Congreso- respecto de las reformas a la Constitución de $1833^{126}$, o un Carlos Estévez celebrando la Constitución de 1925 como una versión reformada de la 1833, pero manteniendo sus "principios esenciales" ${ }^{27}$. También encontramos el escepticismo que subyacía la negativa de Alessandri de someter su proyecto de Constitución a una Asamblea Constituyente $^{128}$. En fin, suma y sigue. No se trata acá de ser parcialmente selectivo, y en tan apretada enumeración, intentar demostrar que la evolución y el incrementalismo constitucional ha sido el ethos del constitucionalismo chileno previo a la Constitución actual; muy por el contrario, basta mostrar que ha sido parte importante de este, y más importante aún debe seguir siéndolo hoy como estándar de cambio constitucional.

El debate sobre la legitimidad de origen de la Constitución actual es tan controversial $^{129}$ como improductivo. La constitución alemana es un gran ejemplo de cómo la ilegitimidad de origen de una constitución -en este caso impuesta por los aliados- permite una práctica constitucional que la redime $\mathrm{e}^{130}$. En este sentido, existe controversia respecto de si la práctica constitucional posterior al retorno a la democracia en Chile -la que se manifiesta no solo en las sentencias del Tribunal Constitucional o de los tribunales superiores de justicia, sino en los reglamentos y prácticas de las cámaras del Congreso Nacional, los

ción más general al cambio constitucional en Latinoamérica de los últimos años, con algunos capítulos dedicados específicamente al nuevo constitucionalismo latinoamericano.

124 Existe una interesante y renovada literatura desde el ius publicismo que se ha referido a aspectos relevantes de la evolución de la tradición constitucional chilena. Particularmente significativa es Cristi y RuIz-TagLe (2008), Zapata (2008) y Tschorne (2012). También es un aporte interesante desde la sociología del derecho el de Faúndez (2011).

125 Junto con Errázuriz, sostenían en sus "Bases para la Reforma” de 1850 que: "Los defectos de esa Constitución, que siempre hemos reconocido y confesado; sus errores; sus transgresiones del sistema representativo, que pudieron ser tolerados en los días siguientes a una Revolución, en los cuales el país anhelaba orden y necesitaba un poder fuerte que diera quietud y seguridad, no son hoy inconciliables con la situación en que se halla este país y opuestos a su desarrollo y progreso. Oponerse a la reforma es violentar a la Nación que la emprenda por sí misma. Mantener una organización política que fue creada para una época de anarquía es lo mismo que confundir dos épocas muy diversas y negar que Chile se encuentra en estado de pedir más justicia y más libertad”. Citados por Andrade (1971) p. 10.

126 Ver Ruiz-Tagle (2008) p. 103.

127 Sostuvo Estévez: "La reforma constitucional de 1925, que es en nuestra historia política una parte de ese proceso evolutivo tuvo a mi juicio un aspecto de importancia que es necesario recordar: no pretendió destruir lo que el esfuerzo de casi un siglo de vida constitucional había creado en nuestro país, respetó las tradiciones que la experiencia política había aquilatado, solo procuró amoldar las instituciones existentes a las modernas orientaciones del derecho público. La Constitución de 1925, es la misma de 1833, los principios esenciales de aquella los encontramos en esta”. EsTÉvez (1942) p. 47.

128 Citado por Andrade (1971) pp. 28-29.

129 Muy tempranamente desarrollado por Cumplido (1983). Ver también Silva Bascuñán (1997), Barros (2004) y Couso (2012).

130 Ver Jackson y Tushnet (2006) pp. 285. Japón también podría ser un buen ejemplo. Ver JACKSON y Tushnet (2006) p. 286. 
dictámenes de la Contraloría General de la República, etc., todo aquello que forma parte de la Constitución "no escrita"131-, junto con las grandes reformas de 1989 y 2005 -en el marco de más de treinta leyes de reforma constitucional-, ha sido o no capaz de otorgarle a la Constitución actual legitimidad de ejercicio.

Para quienes nos inclinamos por la afirmativa -incluyendo a constitucionalistas progresistas moderados ${ }^{132}$-, la pregunta central que el debate constitucional debe contestar es la siguiente: ¿cuáles elementos de la Constitución actual forman parte de la tradición constitucional chilena y cuáles, en cambio -no siendo aquellos que podrían ser considerados, siguiendo a Estévez, "las modernas orientaciones del derecho público"133 - repugnan dicha tradición? Se entregaran algunas luces en la siguiente sección.

Segundo, una aproximación minimalista a la Constitución y al cambio constitucional debe echar mano a la evidencia empírica disponible. Lamentablemente, en Chile la evidencia en esta materia es escasa. Ello es un problema en la medida en que abre un espacio desmesurado y desproporcionado a la ideología, perpetuando en el debate falsos dilemas. Destacan, por ejemplo, el trabajo crítico sobre leyes orgánico-constitucionales de Sierra $^{134}$, o el de Verdugo que, analizando la jurisprudencia en sede de control preventivo obligatorio del Tribunal Constitucional entre 2006 y 2009, muestra que se trata de una verdadera "toma de razón", de escaso impacto y relevancia ${ }^{135}$. Por otra parte, Fermandois, ha entregado evidencia general cuantitativa respecto de las reformas constitucionales entre 1989 y 2009 y su taxonomía, sosteniendo que las críticas en torno a la excesiva rigidez de la Constitución no ha sido obstáculo para modificarla profusamente ${ }^{136}$.

Con todo, la pobreza en este ámbito es evidente -lo que, por lo demás, demuestra el déficit de la academia legal en particular, pero de la cultura jurídica en general, a la hora de examinar el derecho desde otras disciplinas científicas-, contrastando con un renovado interés por el estudio de las constituciones, sus ciclos, los procesos de creación y cambio constitucional, en el derecho constitucional comparado en la última década. En este sentido, la evidencia ha entregado información valiosa respecto de los elementos que explican la creación constitucional, el rol de las Asambleas Constituyentes y los factores que las gati-

\footnotetext{
131 Sobre el concepto de constitución "no escrita" ver especialmente Tribe (2008) y AmAR (2012).

132 Alejandro Silva Bascuñán -probablemente el más importante constitucionalista del siglo XX, y prominente intelectual social cristiano-, por ejemplo, sostuvo, muy tempranamente (1997) que: "Lo que pudo calificarse primero como una Constitución otorgada, más adelante como una Carta pactada, hoy debe calificarse como una Ley Fundamental que, sin perjuicio de las críticas favorables o adversas que merezca su texto, se ha hecho democrática en virtud de las tres aprobaciones populares recién recordadas [plebiscito de octubre de 1988, reforma constitucional plebiscitada en julio de 1989, y elección presidencial y parlamentaria de diciembre de 1989], por ser íntegramente modificable y haber sido, en fin, objeto ya de varias reformas de acuerdo con su propio texto". Silva Bascuñán (1997) p. 243. Para Nogueira (2008), la reforma constitucional de 2005 elimina los últimos enclaves autoritarios de la Constitución. Destaca también ZaPATA (2008) pp. 169-170, valorando positivamente la reforma constitucional de 2005, en la medida en que devolvía a Chile a su tradición constitucional democrática. Sin embargo, en ZAPATA (2014). pasa a tener una posición más crítica; en todo caso resalta que los cambios de 2005 fueron importantes y profundos.

133 Estévez (1942) p. 47.

134 Ver Sierra (2011).

135 Ver Verdugo (2010).

136 Ver Fermandois (2010) p. 287.
} 
llan, las condiciones que permiten asegurar la continuidad de una Constitución en el tiempo, la capacidad de innovación en la inclusión de nuevos derechos, entre otros ${ }^{137}$.

Asimismo, ha comenzado a surgir evidencia específica respecto del proceso constitucional en Latinoamérica ${ }^{138}$. Particularmente interesante resulta el trabajo de Negretto, quien establece la importancia del liderazgo presidencial para gatillar procesos de cambio constitucional, y las condiciones políticas de su coalición (y el estado en el que se encuentra la oposición), lo que será decisivo en el tipo de arreglo constitucional que se buscará promover -especialmente la forma de configurar las potestades presidenciales vis a vis las potestades del Congreso- ${ }^{139}$.

En tercer lugar, unas de las razones que explican cierto escepticismo respecto de los procesos constitucionales (a través de asambleas constituyentes) en nuestro continente -más allá de las experiencias concretas en cada uno de estos países, y las lecciones positivas o excesos y arbitrariedades cometidos-, dice relación con la importancia que han tenido las ideas del denominado "nuevo constitucionalismo latinoamericano". Este enfoque ha desarrollado la tesis de la "unidad del poder", esto es, la legitimidad de la concentración del poder público en torno al Presidente de la República -lo que ha incluido, por ejemplo, desahuciar la noción de que la Judicatura deba ser independiente- para poder realizar transformaciones sociales ${ }^{140}$. El hecho de que las naciones del continente no hayan experimentado el Estado Social, en palabras de dos de sus principales exponentes, Viciano y Martínez, induce a pensar que las luchas sociales fueron el fundamento de la aparición de esta nueva corriente, haciendo que los recientes procesos constituyentes latinoamericanos pasen "a ser procesos necesarios en el devenir de la historia" ${ }^{141}$. Este nuevo constitucionalismo "recupera el origen radical-democrático del constitucionalismo jacobino, dotándolo de mecanismos actuales que puedan hacerlo más útil en la identidad entre voluntad popular y Constitución" ${ }^{142}$. Asimismo, "como no podía ser de otra manera", sostienen estos autores, "la necesidad de superar las desigualdades económicas y sociales y de plantear constitucionalmente el nuevo papel del Estado en la economía se traduce en amplios capítulos económicos" 143 , lo que es obviamente "una reivindicación de los movimientos sociales que dieron vida a los procesos constituyentes, y que cuenta con su traslación en la perspectiva de un desarrollo económico alternativo" ${ }^{\text {144 }}$.

Se trata, en suma, de un enfoque que es contrario a elementos centrales, no solo de una democracia liberal, sino del constitucionalismo en su intento de limitar el poder estatal. Para el nuevo constitucionalismo latinoamericano el principio de separación de poderes, sobre la base de un sistema de pesos y contrapesos, o la autonomía de la Judicatura, parecen ser escollos para sortear que arreglos institucionales sanos.

\footnotetext{
137 Ver, por ejemplo, Elkins y otros (2010), Dixon (2011), y Ginsburg (2011) y (2012).

138 Destacan, por ejemplo, Nolte y Schilling-Vacaflor (2012) y Negretto (2013).

139 Ver Negretto (2012) y (2013).

140 Ver Couso (2013).

141 Viciano y Martínez (2010) p. 20.

142 Viciano y Martínez (2010) p. 18.

143 Viciano y Martínez (2010) p. 37.

144 Viciano y Martínez (2010) p. 38.
} 


\subsection{DÉFICITS Y CONTROVERSIAS CONSTITUCIONALES, Y SU REFORMA A TRAVÉS DEL PRISMA}

\section{MINIMALISTA}

Un buen punto de partida para una aproximación minimalista como la que se ha desarrollado en este artículo al debate constitucional chileno, es la expresión que ha acuñado Correa en el último tiempo, que refleja, de manera perfecta, el ethos de una posición como la que se ha defendido en este artículo (al menos desde la perspectiva del minimalismo sustantivo): al debate constitucional debemos asistir con una goma más que con un lápiz ${ }^{145}$. Se trata de una reflexión que no es solo profunda sino atingente, en la medida en que, como podrá observarse a continuación, algunos de los déficits y controversias constitucionales más relevantes pasan por quitar reglas, no agregar.

Hoy, en primer lugar, la Constitución cuenta con arreglos institucionales deficitarios en materia de descentralización tanto política y administrativa, como fiscal. Ello se amplifica ante la inexistencia de mecanismos institucionales que permitan una participación ciudadana temprana en una serie de decisiones públicas. Se trata de un ámbito de subaplicación del principio de subsidiariedad. Este controversial principio, se ha pensado en la institucionalidad chilena, exclusivamente vinculado a materias económicas y sociales, al mayor o menor rol del Estado en diversos mercados y espacios mixtos (educación o salud), pero no en su versión competencial, esto es, en la manera de entender la distribución de potestades en el ámbito de lo local, lo regional y lo nacional.

Así, en esta materia, no se trata solo de radicalizar el proceso de descentralización mediante una construcción más agresiva del principio de subsidiariedad. Ello es condición necesaria pero no suficiente. La tradición constitucional chilena -salvo en el periodo de fundación de la República cuando se intentó ensayar un régimen federal-, entrega pocas directrices y experiencia. En efecto, es posible que Chile avance en el mediano plazo hacia un Estado regional, aquilatando las experiencias en el derecho comparado para compensar los déficits de su historia constitucional. Radicalizar la descentralización es importante desde la perspectiva minimalista en la medida en que se deja a espacios competenciales diferentes al nacional, la definición de aspectos relevantes de las identidades regionales y locales, en decisiones políticas, administrativas y fiscales. Por lo demás, ello debe ir acompañado de una revisión crítica de los excesos de regulación constitucional en materia de gobiernos regionales y locales que es posible encontrar hoy en la Constitución.

Una segunda cuestión, dice relación con el controversial principio de subsidiariedad. Se trata de un principio que, originalmente pensado para entregar criterios de actuación de los privados y el Estado en diversos ámbitos económicos y sociales - privilegiando, en la medida de lo posible, el accionar de los primeros (dimensión negativa), a menos de que se cumplan ciertas condiciones que hagan necesario el apoyo estatal (dimensión positiva) ${ }^{146}$, ha sido cuestionado desde el constitucionalismo progresista tanto por su naturaleza jurídi-

145 Ver Correa (2013) pp. 26-27: “... aun cuando existen buena razones para entender que la Constitución del 80 está lejos de ser adecuada para enmarcar nuestro sistema democrático, podría no haber llegado la hora de escribir una nueva, sino de instalar un debate en que triunfe la idea de "deconstruir" las formas excesivamente ideológicas de la que nos rige y de abrir más y no menos espacio al juego político. Es la hora, postulo en este artículo, de entrarle a la Constitución con una goma más que con un lápiz”.

146 Ver Fermandois (2001) y García (2010). 
ca, como el ser ajeno a la tradición constitucional chilena ${ }^{147}$. También ha sido criticado, por el rol central que jugaría en la Constitución para consagrar un orden neoliberal ${ }^{148}$.

Se trata de un debate en que no hay acuerdos mínimos respecto de aspectos sustantivos. Por ejemplo, no existe consenso respecto de qué es lo que está realmente consagrado en la Constitución -el artículo $1^{\circ}$ inciso tercero de la Constitución consagra el principio de autonomías sociales-; jurisprudencia relevante reciente del Tribunal Constitucional (TC) hoy hace inverosímil una lectura libertaria de este ${ }^{149}$; no existe evidencia que demuestre el real impacto que ha tenido, o el que haya actuado como estándar de control de constitucionalidad de la ley, como elemento de veto o censura; etc. Además, no deja de ser interesante que algunos críticos de la subsidiariedad, sobre la base de argumentos minimalistas en torno a su lejanía con la tradición constitucional chilena, hoy promuevan, como alternativa, un Estado Social de Derecho, basado en el principio de solidaridad. Paradójicamente, se propone una suerte de neoliberalismo con signo negativo de manera explícita. Se está, en suma, ante un debate de fuerte contenido ideológico.

Con todo, una aproximación minimalista en este ámbito, deferente con la tradición constitucional chilena, lleva a la necesidad de examinar el rol de este principio en el ordenamiento constitucional chileno. Volver a los principios clásicos de libertad e igualdad, aquilatando de buena manera la experiencia de las últimas décadas en el mundo, en torno a que el Estado ha dejado de ser un actor relevante como productor en una serie de mercados de bienes y servicios, pasando a ser regulador y estimulando más bien reglas de competencia y transparencia, parece una alternativa posible. También puede ser una alternativa, siguiendo la jurisprudencia del TC antes citada, un entendimiento conjunto de la subsidiariedad y la solidaridad. Esta última es, por ejemplo, la posición de Zapata ${ }^{150}$.

Lo anterior tiene una dimensión adicional: la constitucionalización de nuevos derechos sociales (por ejemplo, a la vivienda o a la cultura) y/o la extensión de la garantía de la acción de protección a derechos sociales que hoy no la tienen ${ }^{151}$. ¿Cuántos derechos resiste la Constitución? es la pregunta que se formuló hace no mucho Aldunate ${ }^{152}$. Su respuesta, al igual que la de Correa ${ }^{153}$ y la de este artículo es: pocos y básicos (civiles y políticos). Para Aldunate el riesgo de caer en la trampa del lirismo constitucional es alta; antes lo había dicho Sunstein precisamente en materia de reconocimiento de derechos sociales: "una Constitución es en gran medida un documento jurídico, con tareas concretas. Si la Constitución

\footnotetext{
147 Ver Ruiz-Tagle (2000). Ver también Vallejo y Pardow (2008).

148 Ver Ferrada (2000), Cristi y Ruiz-Tagle (2008), y Atria (2013a).

149 En efecto, un leading case de los derechos sociales como Isapre I (STC Rol Nº76-08), descansa fuertemente en un entendimiento de la subsidiariedad como solidaridad; o, un fallo más reciente como Franja de Primarias (STC Rol N² 2487-13 ha puesto el énfasis en la "adecuada autonomía” que gozan los cuerpos intermedios, permitiendo "adecuada" un interpretación amplia de justificación de interés público para el legislador.

150 Ver Zapata (2014) pp. 113-114.

151 Ver, por ejemplo, Couso y Coddou (2010), Lovera (2010), Jordán (2011) y Zapata (2014).

152 Ver Aldunate (2010).

153 Ver Correa (2010) y (2013).
} 
intenta especificar todo a que quiere comprometerse una sociedad decente, corre el riesgo de pasar a ser un mero pedazo de papel, sin mayor valor en el mundo real"154.

Finalmente en esta materia, no se puede dejar de hacer notar que una aproximación minimalista que es escéptica de la regulación de derechos económicos y sociales en la Constitución, lo es también de una regulación frondosa, meticulosa, del desarrollo de los derechos civiles y políticos, básicos. Un buen ejemplo en la Constitución actual se encuentra en la regulación de la libertad de asociación o del derecho de propiedad. En ambos casos, conviene ir al debate constitucional con goma.

Por lo demás, como he sostenido en otro artículo, los derechos sociales se están construyendo sobre la base de la subsidiariedad, no contra ella ${ }^{155}$, y su judicialización genera espacios para el activismo judicial, esto es, el que los jueces y no el proceso político tome las decisiones de política pública (por ejemplo, en materia de legislación social) más relevantes del país ${ }^{156}$.

Lo anterior es paradójico porque el "momento constitucional" desde el progresismo precisamente se ha justificado para avanzar el principio democrático, contra las instituciones contramayoritarias (y los jueces lo son). Es también paradójico, si se sigue a una de las voces más relevantes del constitucionalismo progresista del continente, Gargarella, porque la estrategia progresista de judicializar los derechos sociales, obvia un punto central: lo relevante para avanzar por este camino es la "sala de máquinas" de la Constitución; transformaciones sociales duraderas y democráticas requieren examinar los arreglos políticos orgánicos y procedimentales que las permitan, por encima del camino de la judicialización de los derechos sociales ${ }^{157}$.

Por otro lado, la tradición constitucional chilena ha conocido al menos una constante desde sus orígenes: el presidencialismo parece indestructible, y cuando se le ha querido erosionar o reemplazar, reaparece con más fuerza (y potestades). Hoy es posible observar una serie de patologías del hiperpresidencialismo chileno, algunas con efectos sistémicos negativos. La Constitución actual consagra un hiperpresidencialismo o cesarismo presidencial, marcado, particularmente -y en lo que se distingue del presidencialmente clásico norteamericano- por potestades legislativas exorbitantes en manos del Presidente de la República $^{158}$.

Sin entrar al detalle de las reformas en este ámbito, parece conveniente, avanzar hacia un esquema presidencial clásico, no solo morigerando las potestades legislativas del Presidente, sino, y junto con ello, aumentando las potestades del Congreso, tanto de fiscalización de la Cámara de Diputados, como de contrapeso en nombramientos por parte del Senado. Asimismo, y una de las cuestiones relevantes por las cuales ciertos procesos

\footnotetext{
154 Sunstein (1993) p. 36.

155 Ver García (2010a).

156 Ver García y Verdugo (2013).

157 Ver Gargarella (2013).

158 Ver Fermandois y García (2009). Aninat (2006), por otra parte, sostiene que los poderes constitucionales del Presidente si bien le permiten controlar la agenda legislativa, no tiene la capacidad unilateral de modificar el statu quo. Ello, junto a las supermayorías legales requeridas y el sistema electoral binominal, configuran un sistema legislativo cooperativo.
} 
constituyentes en la región y los aportes intelectuales del nuevo constitucionalismo latinoamericano deben ser críticamente examinados, dicen relación con nuevas fórmulas, directas e indirectas, de concentración del poder presidencial. Para el caso chileno, reforzar la autonomía y capacidades institucionales del Poder Judicial y las de la Contraloría General de la República ${ }^{159}$, resultan necesarios. Del mismo modo, en Chile aún no se ha abierto de manera sustantiva el debate en torno a potenciar otras autonomías constitucionales y legales, obviamente bajo estrictos criterios de transparencia y rendición de cuentas ${ }^{160}$.

Adicionalmente, la discusión en torno a reformas a nuestro régimen político deben ir de la mano con la discusión -hoy ya eterna- de reemplazo del sistema electoral parlamentario. El actual sistema binominal no solo ha cumplido un ciclo -si el balance es positivo o negativo es sinónimo de controversia-, sino que algunas de las patologías -trasladar la competencia entre bloques hacia una intrabloques, generándose incentivos para minimizar la competencia- se han acentuado. Con todo, el reemplazo del sistema electoral, debe tener a la vista el régimen político. Y si bien nuestra tradición constitucional ha estado basada en un sistema electoral proporcional, existe bastante evidencia que muestra los riesgos de contar con un sistema proporcional bajo un régimen político presidencial ${ }^{161}$. Es por ello que tanto fórmulas proporcionales moderadas como alternativas mayoritarias son compatibles con el presidencialismo.

Finalmente, la Constitución cuenta con un uso excesivo de instituciones y mecanismos contramayoritarios. Algunos de ellos impactan negativamente el proceso democrático, no logrando balancear adecuadamente el imperativo de una democracia constitucional: la mixtura entre el ideal regulativo del constitucionalismo -limitando el poder público para proteger los derechos y libertades individuales- y el ideal democrático -basado en el principio de mayoría-, y que transforma a la Constitución tanto en fuente de restricción, como habilitante, siendo ambas dimensiones inseparables y fundamentales. Así, no solo se ha incorporado a la "sala de máquinas" de la Constitución, una serie de técnicas contramayoritarias - muchas de ellas desde el derecho comparado, y por lo mismo, con escasa biografía en nuestra tradición constitucional lo que hace ser doblemente exigentes al examinarlas y evaluar su sentido-, sino que las ha aplicadas en dosis altas ${ }^{162}$.

159 Ver Cordero (2010) y (2012).

160 Ver Cordero y García (2012), y García y Verdugo (2010).

161 Ackerman sostiene que: “... la forma más tóxica de división de poderes es la combinación constitucional de 1) un presidente popularmente electo junto con 2) un Congreso electo por un sistema de RP [representación proporcional parlamentaria]”. AcKerman (2007) p. 40. Para el debate en Chile ver Fontaine y otros (2009).

162 En principio, no soy contrario al uso de técnicas contramayoritarias en la Constitución, sobre la base de que se cumplan ciertas condiciones, y que no constituyan un obstáculo deliberado al principio democrático, sino buscando equilibrarlo con el respeto al principio de los derechos humanos. Sin que sea un planteamiento teórico elaborado, estas condiciones son, a mi juicio, las siguientes: se asuma que son técnicas que no tienen un valor en sí mismo -ie., son instrumentales-, porque buscan proteger ciertos bienes específicos, que son considerados especialmente valiosos por la comunidad; operan y tienen consecuencias sistémicas -se trata de un balance que no solo impacta lo orgánico y procedimental, sino que se extiende en sus efectos a los derechos y libertades individuales-; su consagración es explícita -evitando que sean asumidas como parte de la Constitución "material" o sobre la base de interpretaciones finalistas, o bajo la lógica de potestades implícitas-, y, la comunidad y sus representes tienen los "ojos bien abiertos" respecto de los costos democráticos del uso de las mismas. Tomo esta última condición de una similar de Zapata (2008) p. 67. 
Así, por ejemplo, la existencia de supermayorías legales, en particular el caso de las leyes orgánicas constitucionales no solo son excepcionales en el derecho comparado, sino que ajenas a nuestra tradición constitucional. Su eliminación o revisión profunda a la baja, parecen sensatas y acorde, entonces, a nuestra tradición constitucional y la evidencia comparada. Por el contrario, la rigidez constitucional, sin embargo, y que hoy exige como regla general un quórum de $3 / 5$ para la aprobación, modificación y derogación de la mayoría de las normas constitucionales, es una técnica presente en el derecho comparado. Porque si bien no estuvo presente en la Constitución de 1925, hoy la evidencia que nos entrega el derecho comparado muestra que se trata de un aprendizaje relevante de las constituciones posteriores a la postguerra, y tiene efectos positivos y moderados, que no inhiben la reforma constitucional ${ }^{163}$.

Asimismo, fórmulas moderadas de revisión judicial (control de constitucionalidad de la ley) no solamente las encontramos en diversas democracias desarrolladas ${ }^{164}$, sino que en países de tradición continental en su fase preventiva. La tradición constitucional chilena incorporó dicha fórmula en la importante reforma de 1970 a nuestro sistema constitucional ${ }^{165}$. Las potestades actuales del TC, no solo deben ser evaluadas entonces bajo la evidencia, el derecho comparado, sino también contra nuestra propia tradición constitucional y el sentido institucional que se le otorgó. Por lo demás, un enfoque de la revisión judicial sobre bases procedimentales, más que sustantivas, parece ser una alternativa que conversa particularmente bien con el enfoque minimalista ${ }^{166}$.

\section{CONCLUSIONES}

El presente artículo ha presentado los lineamientos conceptuales que fundamentan una aproximación minimalista a la Constitución y al cambio constitucional, sobre la base del examen de literatura reciente en esta materia, destacando el que, desde una perspectiva sustantiva, la constitución no busca ni pretende zanjar las controversias sociales fundamentales; no es la constitución un proyecto acabado, un estado o etapa final, sino una actividad, un proceso político continuo; su contenido está marcado por arreglos institucionales predominantemente orgánicos y procedimentales, y básicos en materia derechos y libertades individuales; y en donde la existencia de potestades de revisión judicial de la ley, deben ir acompañadas de una enfoque minimalista en su ejercicio. Asimismo, respecto del cambio constitucional se ha destacado el pensamiento de Burke como un punto de partida relevante para el gradualismo, como también para mantener una actitud escéptica no solo frente al cambio radical, sino a su promoción desde una perspectiva puramente abstracta y teórica; el que la Constitución y el proceso constituyente sea mejor entendida como una actividad, implica que esta esté de manera permanente abierta a la renegociación constitucional, siendo entonces el proceso constituyente uno continuo y contingente; la importancia de mini-

\footnotetext{
163 Ver Elkins y otros (2010).

164 Ver Ginsburg (2002).

165 Ver Frei y otros (1970) y Piedrabuena (1970).

166 Ver Ely (1980).
} 
mizar la distinción entre política constitucional (momento constitucional, intervalos fijos o periodos de discusión constitucional) y política ordinaria; una especial preocupación por el problema de la irreversibilidad, esto es, la magnitud de los costos del cambio; y recalcar la particular solemnidad de la reforma constitucional.

Asimismo, y a la luz de los argumentos conceptuales antes expuestos, y ciertos elementos contextuales presentes en el debate chileno, se han analizado algunos temas destacados de la controversia constitucional actual en Chile, intentando entregar lineamientos para abordarlos desde la perspectiva minimalista. Se trata de una aproximación que rescata la tradición constitucional chilena de manera crítica, considerando la evidencia empírica, tanto nacional como comparada, buscando una sana y sensata evolución constitucional. Se trata de un enfoque alternativo a las miradas maximalistas hoy existentes.

\section{BIBLIOGRAFÍA}

Ackerman, Bruce (1991): We The People I. Foundations (Cambridge, Harvard University Press).

Ackerman, Bruce (1995): "Higher Lawmaking”, en Levinson, Sanford (editor): Responding to imperfections. The theory and practice of constitutional amendment (New Jersey, Princeton University Press): pp. 63-88.

Ackerman, Bruce (1998): We The People II. Foundations (Cambridge, Harvard University Press).

Ackerman, Bruce (2007): La nueva división de poderes (México D.F., Fondo de Cultura Económica).

Ackerman, Bruce (2011): La Constitución viviente (Madrid, Barcelona, Marcial Pons).

Aldunate Lizana, Eduardo (2010): “¿Cuántos derechos resiste la Constitución?”, en Fuentes SAAvedra, Claudio (editor): En nombre del pueblo: debate sobre el cambio constitucional en Chile (Santiago, Ediciones Boell Cono Sur): pp. 246-250.

Amar, Akhil (2006): America's Constitution. A Biography (New York, Random House).

(2012): America's Unwritten Constitution (New York, Basic Books).

Andrade Geywitz, Carlos (1971): Elementos de Derecho Constitucional Chileno (2a edición, Santiago, Editorial Jurídica de Chile).

Aninat Urrejola, Cristóbal (2006): "Balance de poderes legislativos en Chile. ¿Presidencialismo exagerado o base de un sistema político cooperativo?”, Política, vol. 47: pp. 127-148.

Atria Lemaitre, Fernando (2010): "Participación y alienación política: el problema constitucional”, en Fuentes SaAvedra, Claudio (editor): En nombre del pueblo: debate sobre el cambio constitucional en Chile (Santiago, Ediciones Boell Cono Sur): pp. 163-190.

Atria Lemaitre, Fernando (2013): La Constitución Tramposa (Santiago, LOM Ediciones).

Atria Lemaitre, Fernando (2013a): Neoliberalismo con rostro humano. Veinte años después (Santiago, Catalonia).

Atria Lemaitre, Fernando (2014): "La Constitución tramposa y la responsabilidad del jurista”, en Zúníga Urbina, Francisco: Nueva Constitución y momento constitucional (Santiago, LegalPublishing): pp. 15-49. 
Baeza Fernández, Mario (2013): La Constitución contra sí misma. Precariedad de derechos y reforma constitucional en Chile (Santiago, LegalPublishing).

BARros, Robert (2004): Constitutionalism and Dictatorship (Cambridge, Cambridge University Press).

BICKel, Alexander (1986): The least dangerous branch: The Supreme Court at the bar of politics (2a edición, New Haven, Yale University Press).

Bellamy, Richard (2010): Constitucionalismo Político. Una defensa republicana de la constitucionalidad de la democracia (Madrid, Barcelona, Marcial Pons).

Burke, Edmund (1996): Textos Políticos (2a reimpresión, México, Fondo de Cultura Económica).

Choudhry, Sujit (2008): “Ackerman's higher lawmaking in comparative constitutional perspective: Constitutional moments as constitutional failures?”, International Journal of Constitutional Law, vol. 6, n.2: pp. 193-230.

Contesse Singh, Jorge (2008): "Las instituciones funcionan: la falta de diálogo constitucional en Chile", Revista de Derecho y Humanidades: vol. 14: pp. 51-73.

Cordero Vega, Luis (2010): "La jurisprudencia administrativa en perspectiva: entre legislador positivo y juez activista”, Anuario de Derecho Público 2010 de la Universidad Diego Portales: pp. 415-435.

Cordero Vega, Luis y José Francisco García García (2012): "Elementos de discusión sobre Agencias Independientes: el caso de las Superintendencias", Anuario de Derecho Público 2012 de la Universidad Diego Portales: pp. 415-435.

Correa Sutil, Jorge (2010): “Constitución Política y derechos económicos y sociales”, en Fuentes SAAVEDRa, Claudio (editor): En nombre del pueblo: debate sobre el cambio constitucional en Chile (Santiago, Ediciones Boell Cono Sur): pp. 246-250.

Correa Sutil, Jorge (2013): “¡Ha llegado la hora de una Nueva Constitución?”, Anuario de Derecho Público 2013 de la Universidad Diego Portales: pp. 21-35.

Couso Salas, Javier (2012): "Trying democracy in the shadow of an authoritarian legality: Chile's transition to democracy and Pinochet's Constitution of 1980", Wisconsin International Law Journal, vol. 29: pp. 393-415.

Couso SAlas, Javier (2013): "Las democracias radicales y el nuevo constitucionalismo latinoamericano". Working Paper del Seminario Sela (Yale). Disponible en http://www.law. yale.edu/documents/pdf/sela/SELA13_Couso_CV_Sp_20130420.pdf [fecha de consulta: 1 de febrero de 2014].

Couso Salas, Javier y Alberto Coddou McManus (2010): "Las asignaturas pendientes de la reforma constitucional chilena”, en: Fuentes SAAVEDra, Claudio (editor): En nombre del pueblo: debate sobre el cambio constitucional en Chile (Santiago, Ediciones Boell Cono Sur): pp. 191-213.

Cristi Becker, Renato y Pablo Ruiz-Tagle Vial (2008): La República en Chile. Teoría y práctica del constitucionalismo republicano (Santiago, LOM ediciones).

Cumplido Cereceda, Francisco (1983): Estado de Derecho en Chile (Santiago, Instituto Chileno de Estudios Humanísticos). 
Dixon, Rosalin (2011): "Contitutional amendments rules: a comparative perspective", en Ginsburg, Tom y Rosalin Dixon (editores): Comparative Constitutional Law (Northampton, Edward Elgar): pp. 96-111.

Dorf, Michael C. y Charles F. SABEL: "A Constitution of Democratic Experimentalism", Columbia Law Review: vol. 98, n. 2: pp. 267-473.

Elkins, Zachary, Tom Ginsburg y James Melton (2010): The Endurance of National Constitutions (Cambridge, Cambridge University Press).

ELsTER, Jon (1989): Ulises y las sirenas: estudios sobre racionalidad e irracionalidad (México, Fondo de Cultura Económica).

Elster, Jon (2002): Ulises desatado (Barcelona, Gedisa).

Ely, John H. (1980): Democracy and Distrust. A Theory of Judicial Review (Cambridge, Harvard University Press).

Estévez Gazmuri, Carlos (1942): Reformas que la Constitucion de 1925 introdujo a la de 1833 (Santiago, Universidad de Chile).

FArber, Daniel (1994): "Environmental Protection as a Learning Experience", Loyola of Los Angeles Law Review, vol. 27: pp. 791-808.

Faúndez Bravo, Julio (2011): Democratización, desarrollo y legalidad (Santiago, Ediciones Universidad Diego Portales).

Fermandois Vöhringer, Arturo (2006): Derecho constitucional económico. Tomo I (2a edición, Santiago, Ediciones Universidad Católica de Chile).

Fermandois Vöhringer, Arturo (2010): "De afectos y razones en el debate constitucional”, en Fuentes SaAvedra, Claudio (editor): En nombre del pueblo: debate sobre el cambio constitucional en Chile (Santiago, Ediciones Boell Cono Sur): pp. 287-291.

Fermandois Vöhringer, Arturo y José Francisco García García (2009): “Origen del Presidencialismo Chileno: Reforma Constitucional de 1970, Ideas Matrices e Iniciativa Exclusiva”, Revista Chilena de Derecho, vol. 36, n. 2: pp. 281-311.

Ferrada Bórquez, Juan Carlos (2000): "La Constitución Económica de 1980. Algunas reflexiones críticas", Revista de Derecho, vol. 11: pp. 47-54.

FISS, Owen (2008): “The Perils of Minimalism”, en Theoretical Inquiries in Law, vol. 9: pp. 643-664.

Fontaine Talavera, Arturo, Cristián Larroulet Vignau, Jorge Navarrete Poblete e Ignacio Walker Prieto (2009): Reforma del sistema electoral chileno (Santiago, PNUD).

Frei Montalva Eduardo, Sergio Molina Silva, Enrique Evans de la Cuadra, Gustavo Lagos Matus, Alejandro Silva Bacuñán y Francisco Cumplido Cereceda (1970): La Reforma Constitucional de 1970 (Santiago, Editorial Jurídica de Chile).

García García, José Francisco (2008): "El proceso legislativo sin romance: implicancias para el derecho constitucional chileno", Ius et Praxis, vol.14, n.2: pp. 489-522.

García García, José Francisco (2010): "Criterios para fortalecer la revisión judicial de la regulación económica”, en Actualidad Jurídica, vol. 21: pp. 255-315.

García García, José Francisco (2010a): "Subsidiariedad y derechos económicos, sociales y culturales", en Fuentes SaAvedra, Claudio (editor): En nombre del pueblo: debate sobre el cambio constitucional en Chile (Santiago, Ediciones Boell Cono Sur): pp. 256-259. 
García García, José Francisco y Soto Velasco, Sebastián (2009): "Una mirada económico al diseño constitucional chileno: impacto sobre el proceso legislativo y la acción de los grupos de interés", Ius et Praxis, vol. 15, n.1: pp. 353-372.

García García, José Francisco y Verdugo Ramírez, Sergio (2010): "De las Superintendencias a las Agencias Regulatorias Independientes. Aspectos constitucionales y de diseño regulatorio", Actualidad Jurídica, vol. 22: pp. 263-306.

García García, José Francisco y Verdugo Ramírez, Sergio (2013): Activismo Judicial en Chile. ¿Hacia el Gobierno de los jueces? (Santiago, Ediciones LyD).

Gargarella, Roberto (2013): Latin American Constitutionalism 1810-2010. The engine room of the constitution (Oxford, Oxford University Press).

Gargarella, Roberto y Christian Courtis (2009): "El nuevo constitucionalismo latinoamericano: promesas e interrogantes”, en Serie Políticas Sociales CEPAL n 153. Disponible en: http://www.eclac.org/publicaciones/xml/2/37882/sps153-dds-constitucionalismo.pdf [fecha de consulta: 1 de febrero de 2014].

Garretón Merino, Roberto (2010): “¿Cómo cambiar una Constitución ilegítima”, en Fuentes SAAVEDRA, Claudio (editor): En nombre del pueblo: debate sobre el cambio constitucional en Chile (Santiago, Ediciones Boell Cono Sur): pp. 273-277.

GinsburG, Tom (2002): "Economic analysis and the design of constitutional courts", Theoretical Inquiries in Law, vol. 3: pp. 49-85.

Ginsburg, Tom (2011): “Constitutional endurance”, en Ginsburg, Tom y Rosalin Dixon (editores): Comparative Constitutional Law (Northampton, Edward Elgar): pp. 112-125.

Ginsburg, Tom (editor) (2012): Comparative Constitutional Design (Cambridge, Cambridge University Press).

Holmes, Stephen y Cass R. Sunstein (1995): "The Politics of Constitutional Revision in Eastern Europe", en LeVInson, Sanford (editor): Responding to imperfections. The theory and practice of constitutional amendment (New Jersey, Princeton University Press): pp. 275-306.

Jordán DíAz, Tomás (2011): "El principio de contribución constitucional y la abrogación del principio de subsidiariedad en materia de derechos fundamentales sociales", en FERRADA BóRQUez (coordinador): Estudios de Derecho Público. El principio de separación de poderes. Actas de las XL Jornadas de Derecho Público, 2010 (Santiago, AbeledoPerrotLegalPublishing): pp. 553-573.

JaCKSOn, Vicki y Mark Tushnet (2006): Comparative Constitutional Law (2a edición, New York, Thomson West).

Jowell, Jeffrey y Dawn Oliver (2011): The Changing Constitution (7a edición, Oxford, Oxford University Press).

Kronman, Anthony (1990): "Precedent and Tradition", Yale Law Journal, vol. 99: pp. 1029-1068.

LeVmore, Saul (2010): "Interest groups and the problem with incrementalism”, University of Pennsylvania Law Review, vol. 158: pp. 815-858.

Lerner, Hanna (2011): Making Constitutions in deeply divided societies (Cambridge, Cambridge University Press). 
Levinson, Sanford (1995): "Introduction: Imperfection and Amendability", en LeVInson, Sanford (editor): Responding to imperfections. The theory and practice of constitutional amendment (New Jersey, Princeton University Press): pp. 3-12.

Lijphart, Arend (2004): "Constitutional Design for divided societies", Journal of Democracy, vol. 15, n. 2: pp. 96-109.

Listokin, Yair (2008): "Learning Through Policy Variation”, Yale Law School Faculty Scholarship Series. Paper 557. Disponible en: http://digitalcommons.law.yale.edu/fss_papers/557 [fecha de consulta: 1 de febrero de 2014]

Lovera Parmo, Domingo (2010): "Derechos sociales en la Constitución del 80 (y de 1989 y de 2005)", en Fuentes SaAvedra, Claudio (editor): En nombre del pueblo: debate sobre el cambio constitucional en Chile (Santiago, Ediciones Boell Cono Sur): pp. 217-243.

MuÑoz, Fernando (2013): “'Chile es una república democrática’: la asamblea constituyente como salida a la cuestión constitucional”, en Anuario de Derecho Público 2013 de la Universidad Diego Portales: pp. 60-94.

Negretto, Gabriel L. (2012): "Toward a theory of formal constitutional change: mechanisms of constitutional adaptation in Latin America", en Nolte, Detlef y Almut Schilling-Vacaflor (editors): New Constitutionalism in Latin America. Promises and practices (Burlington, Ashgate): pp. 51-72.

Negretto, Gabriel L. (2013): Making Constitutions. Presidents, parties and institutional choice in Latin America (Cambridge, Cambridge University Press).

Nogueira Alcalá, Humberto, (2008): "La evolución político-constitucional de Chile 1976-2005”, Estudios Constitucionales, vol. 6, n. 2: pp. 325-370.

Nolte, Detlef y Almut Schilling-Vacaflor (editors) (2012): New Constitutionalism in Latin America. Promises and practices (Burlington, Ashgate).

NozIck, Robert (1977): Anarchy, State and Utopia (New York, Basic Books).

Piedrabuena Richards, Guillermo (1970): La Reforma Constitucional. Historia de la Ley 17.284, sus principales alcances y posición de los partidos políticos (Santiago, Ediciones Encina Ltda.).

PIsarello, Gerardo (2010): "El nuevo constitucionalismo latinoamericano y la Constitución venezolana. Balance de una década", en Revista Sin permiso. Disponible en: http:// www.rebelion.org/docs/96201.pdf [fecha de consulta: 1 de febrero de 2014].

Rojas SÁnchez, Gonzalo (2013): "Asamblea Constituyente: igolpe de Estado? Una evaluación política y jurídica”, Derecho Público Iberoamericano, vol. 2: pp. 289-299.

Ruiz-Tagle Vial, Pablo (2000): "Principios constitucionales del Estado empresario", Revista de Derecho Público, vol. 62: pp. 49-65.

Ruiz-Tagle Vial, Pablo (2008): "La trampa del neopresidencialismo: la Constitución gatopardo”, en Cristi Becker, Renato y Pablo Ruiz-Tagle Vial: La República en Chile. Teoría y práctica del constitucionalismo republicano (Santiago, LOM ediciones): pp. 197218.

SAbel, Charles F. y William H. Simon (2011): "Minimalism and Experimentalism in the Administrative State", Georgetown Law Journal, vol. 100: pp. 53-93.

SCHOR, Miguel (2016): "Constitutionalism through the looking glass of Latin America", Texas International Law Journal, vol. 41: pp. 1-38. 
Sierra Iribarren, Lucas (2011): "La supramayoría en la potestad legislativa chilena como anomalía democrática”, en Sierra Iribarren, Lucas y Lucas Mac-Clure: Frente a las mayorías. Leyes supramayoritarias y Tribunal Constitucional en Chile (Santiago, Programa de Naciones Unidas para el Desarrollo): pp. 13-168.

Silva Bascuñán, Alejandro (1997): Tratado de Derecho Constitucional. La Constitución de 1980. Antecedentes y génesis (2a edición, Santiago, Editorial Jurídica de Chile), Tomo III.

Sunstein, Cass R. (1993): "Against positive rights", East European Constitutional Review, vol. 2: pp. 35-38.

Sunstein, Cass R. (2001): Designing Democracy: What Constitutions do (Oxford, Oxford University Press).

Sunstein, Cass R. (2001a): One Case at a time. Judicial minimalism on the Supreme Court (Cambridge, Harvard University Press).

Sunstein, Cass R. (2005): Radicals in Robes. Why extreme right/wing courts are wrong for America (New York, Basic Books).

Sunstein, Cass R. (2006): "Burkean Minimalism”, Michigan Law Review, vol. 105: pp. 353-408.

Sunstein, Cass R. (2006a): "Irreversible and catastrophic", Cornell Law Review, vol. 91: pp. 841-883.

Sunstein, Cass R. (2007): "Beyond Judicial Minimalism”, Tulsa Law Review, vol. 43: pp. 825-862.

Sunstein, Cass R. (2009): A Constitution of Many Minds (New Jersey, Princeton University Press).

Tribe, Laurence H. (2008): The Invisible Constitution (Oxford, Oxford University Press).

Tschorne Venegas, Samuel (2012): "Constitucionalismo autoritario y estabilidad política chilena. El lugar del Derecho y las instituciones en la historia de Chile (1820-1925)", Yale Law School Seminario en Latinoamerica de Teoría Constitucional y PolíTICA (SELA): El Constitucionalismo en transición (Buenos Aires, Libraria): pp. 37-74.

Tushnet, Mark (1999): Taking the Constitution way from the courts (New Jersey, Princeton University Press).

Tushnet, Mark (2008): Weak Courts, Strong Rights. Judicial review and social welfare rights in comparative constitutional law (New Jersey, Princeton University Press).

Urquieta Olivares, Julia (2014): “Una Nueva Constitución para un nuevo Chile”, en ZúNiga Urbina, Francisco: Nueva Constitución y momento constitucional (Santiago, LegalPublishing): pp. 51-80.

Vallejo Garretón, Rodrigo y Pardow Lorenzo, Diego (2008): "Derribando mitos sobre el Estado Empresario", Revista Chilena de Derecho, vol. 35, n. 1: pp. 135-156.

Van de Wyngard Moyano, Jorge (2013): "Los aportes fundamentales de la Constitución de 1980 al sistema jurídico-político y social chileno", Derecho Público Iberoamericano, vol. 2: pp. 277-288.

Varol, Ozan O. (2013): “Temporary Constitutions”, en Lewis \& Clark Law School Legal Studies Research Paper No 08/2013. Disponible en: http://papers.ssrn.com/sol3/papers. cfm?abstract_id=2258188\#\# [fecha de consulta: 1 de febrero de 2014]. 
Vermeule, Adrian (2009): "Many-minds arguments in legal theory", Journal of Legal Analysis, vol.1: pp. 201-248.

Verdugo Ramírez, Sergio (2010): "Control Preventivo Obligatorio: Auge y Caída de la Toma de Razón al Legislador”, Estudios Constitucionales, vol. 1: pp. 201-248.

Viciano, Roberto y Martínez Dalmau, Rubén (2010): "Aspectos generales del nuevo constitucionalismo latinoamericano", en Corte Constitucional de Ecuador: El nuevo constitucionalismo en América Latina (Quito, Corte Constitucional de Ecuador): pp. $9-44$.

Waldron, Jeremy (1999): Law and Disagreement (Oxford, Oxford University Press).

WALDRON, Jeremy (2006): “The core of the case against judicial review”, Yale Law Journal, vol. 115: pp. 1346-1406.

Webber, Jeremy (2000): “Constitutional Reticence”, Australian Journal of Legal Philosophy, vol. 25, n.2: pp. 125-155.

Webber, Grégoire C.N. (2009): The Negotiable Constitution. On the limitation of Rights (Cambridge, Cambridge University Press).

Zapata Larraín, Patricio (2008): Justicia constitucional (Santiago, Editorial Jurídica de Chile).

Zapata Larraín, Patricio (2014): "La Nueva Constitución y el bien común”, en ZúNiga Urbina, Francisco: Nueva Constitución y momento constitucional (Santiago, LegalPublishing): pp. 81-115.

ZúNiga Urbina, Francisco (2009): "Nueva constitución del bicentenario y operación constituyente", Nomos, vol. 3: pp. 243-252.

ZúNiga Urbina, Francisco (2013): "Nueva constitución y operación constituyente. Algunas notas acerca de la reforma constitucional y de la Asamblea Constituyente", Estudios Constitucionales, vol. 11, n. 1: pp. 511-540. 